Article

\title{
Synthesis and In Vitro Anti-Influenza Virus Evaluation of Novel Sialic Acid (C-5 and C-9)-Pentacyclic Triterpene Derivatives ${ }^{\dagger}$
}

\author{
Xu Han ${ }^{1, \ddagger}$, Long-Long Si ${ }^{1, \ddagger}$, Yong-Ying Shi ${ }^{1}$, Zi-Bo Fan ${ }^{1}$, Shou-Xin Wang ${ }^{1,3}{ }^{3}$, Zhen-Yu Tian ${ }^{1}$, \\ Man Li ${ }^{1}$, Jia-Qi Sun ${ }^{1}$, Ping-Xuan Jiao ${ }^{1}$, Fu-Xiang Ran ${ }^{1}$, Yong-Min Zhang ${ }^{2}$, De-Min Zhou ${ }^{1}$ and \\ Su-Long Xiao ${ }^{1, *}$ \\ 1 State Key Laboratory of Natural and Biomimetic Drugs, School of Pharmaceutical Sciences, \\ Peking University, Beijing 100191, China; ax_han@126.com (X.H.); silonglong@bjmu.edu.cn (L.-L.S.); \\ sygne24501@sina.com (Y.-Y.S.); fancyfzb@163.com (Z.-B.F.); shouxinwang@126.com (S.-X.W.); \\ fashankc@163.com (Z.-Y.T.); 18811711762@163.com (M.L.); jiaqi.sun@pku.edu.cn (J.-Q.S.); \\ 15022326072@163.com (P.-X.J.); rfx@bjmu.edu.cn (F.-X.R.); deminzhou@bjmu.edu.cn (D.-M.Z.) \\ 2 Institut Parisien de Chimie Moléculaire, CNRS UMR 8232, Université Pierre \& Marie Curie-Paris 6 , \\ 4 Place Jussieu, Paris 75005, France; yongmin.zhang@upmc.fr \\ 3 School of Pharmacy, Jining Medical University, Rizhao 276826, China \\ * Correspondence: slxiao@bjmu.edu.cn; Tel.: +86-10-8280-5646 \\ + Dedicated to Professor Lihe Zhang on the Occasion of His 80th Birthday. \\ $\ddagger$ These authors contributed equally to this work.
}

Received: 16 May 2017; Accepted: 16 June 2017; Published: 22 June 2017

\begin{abstract}
The emergence of drug resistant variants of the influenza virus has led to a great need to identify novel and effective antiviral agents. In our previous study, a series of sialic acid (C-2 and C-4)-pentacyclic triterpene conjugates have been synthesized, and a five-fold more potent antiviral activity was observed when sialic acid was conjugated with pentacyclic triterpene via C-4 than C-2. It was here that we further reported the synthesis and anti-influenza activity of novel sialic acid (C-5 and C-9)-pentacyclic triterpene conjugates. Their structures were confirmed by ESI-HRMS, ${ }^{1} \mathrm{H}-\mathrm{NMR}$, and ${ }^{13} \mathrm{C}-\mathrm{NMR}$ spectroscopic analyses. Two conjugates (26 and $\mathbf{4 2}$ ) showed strong cytotoxicity to MDCK cells in the CellTiter-Glo assay at a concentration of $100 \mu \mathrm{M}$. However, they showed no significant cytotoxicity to HL-60, Hela, and A549 cell lines in MTT assay under the concentration of $10 \mu \mathrm{M}$ (except compound 42 showed weak cytotoxicity to HL-60 cell line $(10 \mu \mathrm{M}, \sim 53 \%))$. Compounds 20, 28, 36, and 44 displayed weak potency to influenza A/WSN/33 (H1N1) virus (100 $\mu \mathrm{M}, \sim 20-30 \%)$, and no significant anti-influenza activity was found for the other conjugates. The data suggested that both the C-5 acetylamide and C-9 hydroxy of sialic acid were important for its binding with hemagglutinin during viral entry into host cells, while C-4 and C-2 hydroxy were not critical for the binding process and could be replaced with hydrophobic moieties. The research presented herein had significant implications for the design of novel antiviral inhibitors based on a sialic acid scaffold.
\end{abstract}

Keywords: pentacyclic triterpene; sialic acid; influenza virus; structure-activity relationship (SAR)

\section{Introduction}

Influenza is one of the most common and dangerous viral respiratory diseases; it affects three to five million cases of severe illness and leads to approximately 250,000 to 500,000 deaths every year worldwide [1,2]. Based on the antigenic major surface glycoproteins hemagglutinin (HA; 18 subtypes) and neuraminidase (NA; 11 subtypes), it is divided into different subtypes [3]. Currently available options to fight against the respiratory system attack by influenza A viruses include both vaccines and antiviral agents. However, the three types of available vaccines (inactivated influenza vaccine, live 
attenuated influenza vaccine, and recombinant influenza vaccine) have moderate efficacy that varies seasonally due to constant viral evolution [4]. Currently, two classes of anti-influenza drugs have been developed for interruption of specific processes in influenza infection. Amantadine and rimantadine target the M2 protein which is an ion channel allowing protons to move through the viral envelope to uncoat viral RNA, and thus block the release of viral RNA into the cytoplasm [5]. Oseltamivir (Tamiflu) and zanamivir (Relenza), on the other hand, target neuraminidase (NA) protein, inhibiting its enzymatic activity and causing the tethered progeny virus to be unable to escape from its host cells. However, the emergence of drug-resistant influenza viruses has limited the use of those drugs [6-9].

The first step of infection by influenza A virus is mediated by the interaction of sialic acid with the major surface viral glycoprotein haemagglutinin (HA) [10]. The crucial role of HA in the viral lifecycle makes it an attractive target for the development of therapeutics to treat influenza virus infection [11]. Sialic acid (also called as $\mathrm{N}$-acetylneuraminic acid-Neu5Ac), a negatively charged nine-carbon carboxylated monosaccharide, is present at the non-reducing terminal positions of carbohydrate chains of glycoproteins and glycolipids on the cell surface [12]. It is well exploited by many pathogens to attach to and infect cells, and moreover, many pathogens decorate themselves with sialic acid to escape the host immune system [13]. In the last decades, many efforts have been made to develop an anti-influenza drug based on a sialic acid scaffold [14-16]. In fact, the analogs and derivatives of sialic acid have been shown to be potent inhibitors of influenza virus sialidase, and are commercially available [17]. Moreover, other bioactive molecules (such as cholesterol, [18] phospholipid, [19] taxol, [20] deazaflavin, [21] cytidine 5'-monophosphate, [22] and anthraquinone, [23]) have been selected to conjugate with sialic acid to prepare new biologically active molecules. Recently, we have explored potential agents against the influenza virus by the modifications at C-2 of the naturally sialic acid moiety (by conjugation of hydrophobic pentacyclic triterpene (Figure 1), which are widely distributed in the plant kingdom and generally believed to enhance the immunity of host plants and to increase plant resistance to pathogens [24]) with one compound exhibited moderate potency for influenza A/WSN/33 (H1N1) virus with $\mathrm{IC}_{50}$ at $41.2 \mu \mathrm{M}$ [25]. More recently, a five-fold more potent anti-influenza activity was found when sialic acid was conjugated to pentacyclic triterpene via C-4 than to C-2 [26], possibly due to the fact that the big substitute group at C-2 of sialic acid affected the interactions of $\mathrm{COOH}$ with the basic amino acid of HA.

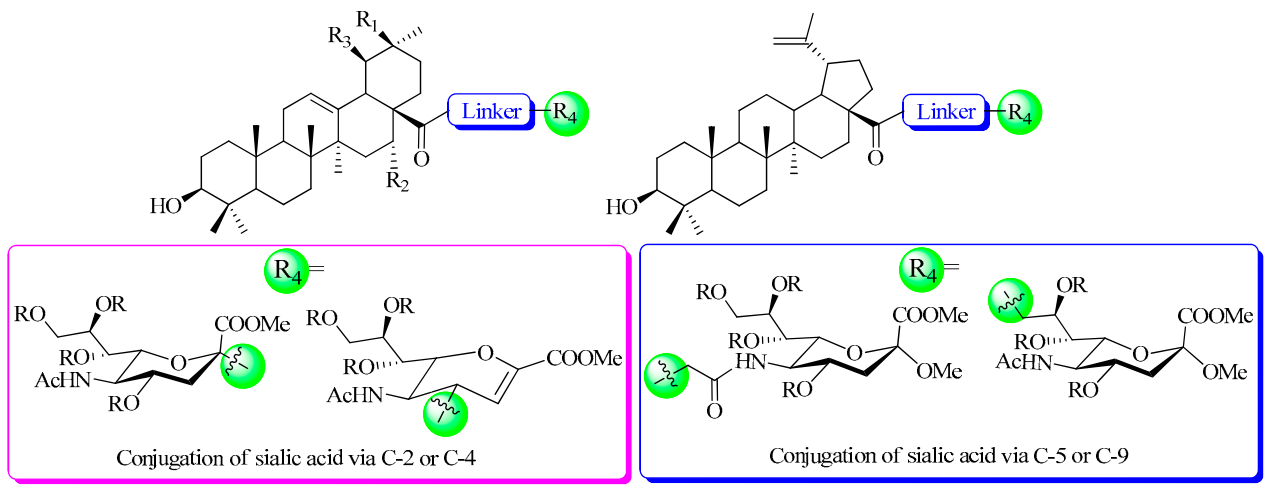

(a)

(b)

Figure 1. The structures of novel pentacyclic triterpene-sialic acid conjugates: (a) From previous work $[25,26] ;$ (b) In this work.

As part of our continued interest in the structurally modified pentacyclic triterpene derivatives as an anti-influenza virus entry inhibitor, $[25,27-30]$ we thought it of value to prepare a range of C-5 and C-9 modified sialic acid derivatives to better explore the antiviral structure-activity relationship (SAR) of sialic acid-pentacyclic triterpene conjugates. We reported herein the synthesis and anti-influenza A/WSN/33 virus activity of a series of C-5 and C-9 modified sialic acid conjugates of pentacyclic triterpene. 


\section{Results and Discussion}

\subsection{Chemistry}

As outlined in our previous work [31], we have achieved the synthesis of the N-propargyl pentacyclic triterpene amides 15-17 and 27 as well as 1-benzotriazolyl pentacyclic triterpene esters 31-33 and 43, respectively.

The C-5 functionalized sialic acid intermediates $\mathbf{9}$ and $\mathbf{1 0}$ were synthesized using the approach shown in Scheme 1. Commercially available sialic acid $\mathbf{1}$ was used as a starting material, and synthesis of the 4,7,8,9-tetra-O-acetyl- $N$-acetylneuraminic acid 4 was performed in moderate yield according to published procedures by Tropper et al. (Scheme 1) [32]. In order to synthesize the C-5 azide substituted intermediate 9 required for cycloaddition reaction, the NHAc group at C-5 was first Boc-protected by treatment with di-tert-butyl dicarbonate $\left(\mathrm{Boc}_{2} \mathrm{O}\right)$ in THF and then de-O-acetylated under Zemplén conditions [33] (followed by re-O-acetylation to provide derivative 7 in $\sim 82 \%$ yield over three steps). Transformation to the azide substituted amide 9 was then performed by removal of the Boc group with TFA in DCM, followed by acylation of the amine. Subsequent catalytic reduction of the 2-azido-acetamide at position C-5 of 9 was achieved by exposure to a $\mathrm{H}_{2}$ atmosphere in the presence of $10 \% \mathrm{Pd} / \mathrm{C}$ in methanol, to afford the $N$-glycylneraminic acid intermediate 10 in $93 \%$ yield (which was used without further purification in the next step).

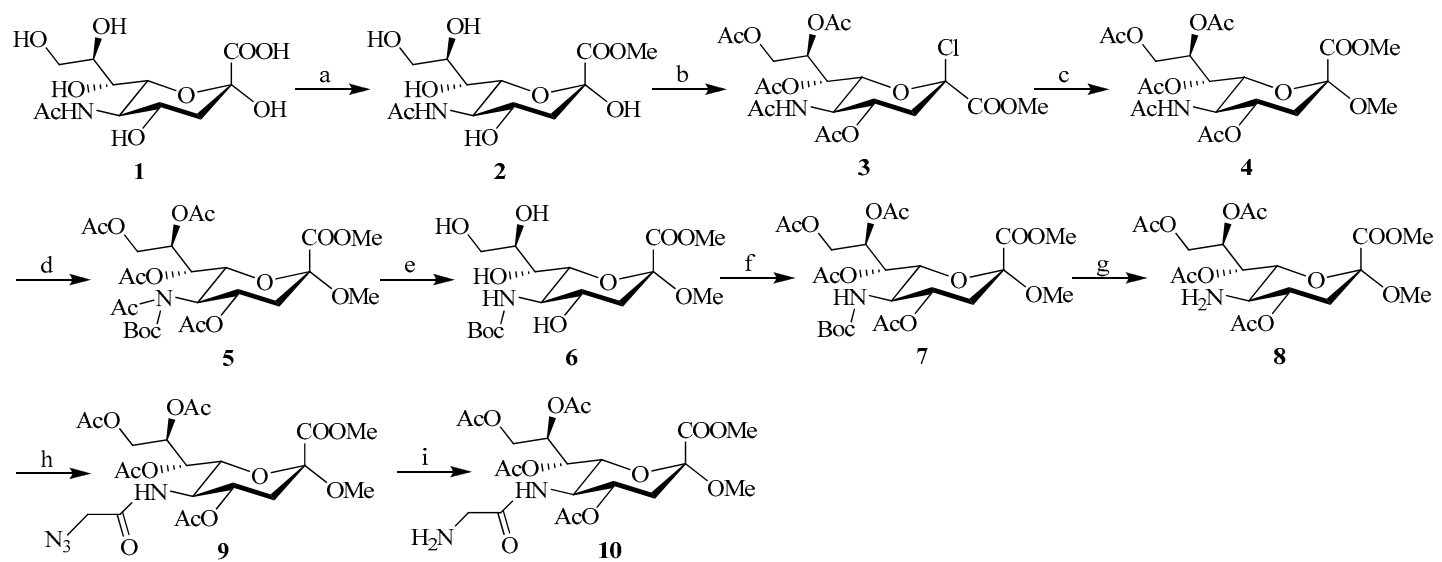

Scheme 1. Reagents and conditions: (a) $\mathrm{MeOH}, \mathrm{H}^{+}$-exchange resin, $\mathrm{RT}, 40 \mathrm{~h}$; (b) $\mathrm{AcCl}, \mathrm{AcOH}, \mathrm{MeOH}$, 24 h; (c) MeOH, RT, 1 h; then $\mathrm{Ac}_{2} \mathrm{O}$, pyridine, RT, 24 h; (d) Boc $2 \mathrm{O}$, DMAP, THF; (e) MeONa/MeOH, 1 h; (f) pyridine, $\mathrm{Ac}_{2} \mathrm{O}$; (g) TFA, DCM; (h) $\mathrm{N}_{3} \mathrm{CH}_{2} \mathrm{COOH}$, EDC, THF; (i) $\mathrm{H}_{2}, \mathrm{Pd} / \mathrm{C}, \mathrm{MeOH}$.

The synthesis of C-9 functionalized sialic acid derivatives 13 and $\mathbf{1 4}$ was accessed from intermediate 4 (Scheme 2). The acetyl groups of 4 were firstly removed under Zemplén conditions, followed by selective mono-tosylation of C-9 hydroxy to afford compound 12 . This compound was followed by nucleophilic substitution with sodium azide in DMF to provide the intermediate 13, and further reduction of the azide group by hydrolygenolysis with $\mathrm{Pd} / \mathrm{C}$ catalysis yielded the corresponding C-9 amine intermediate 14, which was used without further purification in the next step.

Coupling of compound 9 with $N$-propargyl triterpene amides 15-17 and 27 via click reaction yielded the acetyl-protected conjugates 18, 20, 22, and 28, respectively. All the click reactions were performed in $\mathrm{DCM} / \mathrm{H}_{2} \mathrm{O}(1: 1, v / v)$ at room temperature for $12-24 \mathrm{~h}$. In all cases, pentacyclic triterpene-sialic acid conjugates were separated by extraction and purified by column chromatography on silica gel, and the yield after the purification was between $88 \%$ and $95 \%$. In the next step, the Ac groups were removed under Zemplén conditions to give the corresponding conjugates 19, 21, 23, and 29 as the final products quantitatively (Scheme 3). On the other hand, $\mathbf{1 3}$ (which does not contain any protecting groups on the hydroxyl groups) underwent click reaction with $N$-propargyl triterpene 
amides 15-17 and $\mathbf{2 7}$ under similar conditions to directly provide conjugates $\mathbf{2 4 - 2 6}$ and $\mathbf{3 0}$ in yields ranging from $79 \%$ to $87 \%$.

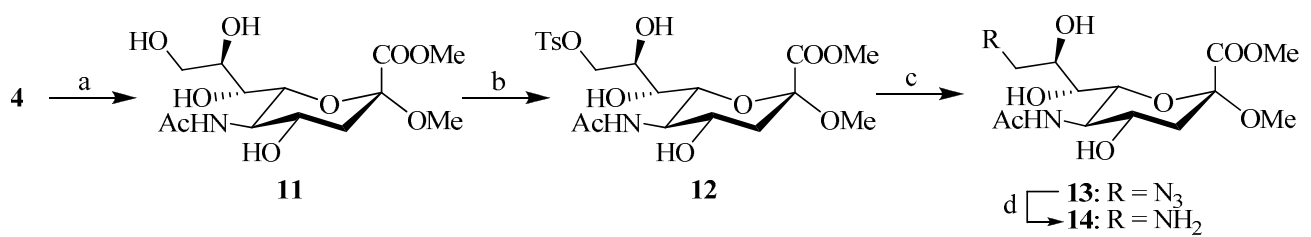

Scheme 2. Reagents and conditions: (a) $\mathrm{MeONa} / \mathrm{MeOH}, 3 \mathrm{~h}$; (b) $p$-TsCl, pyridine; (c) DMF, $\mathrm{NaN}_{3}$, $60{ }^{\circ} \mathrm{C}, 24 \mathrm{~h} ;(\mathrm{d}) \mathrm{Pd} / \mathrm{C}, \mathrm{H}_{2}, \mathrm{CH}_{3} \mathrm{OH}$.

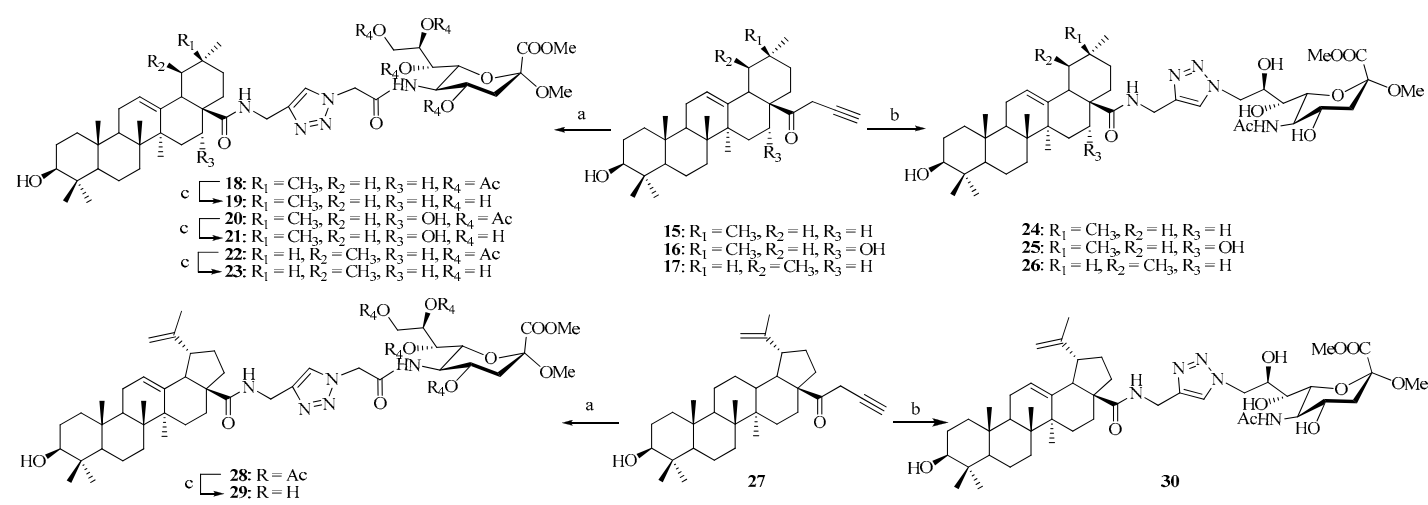

Scheme 3. Reagents and conditions: (a) 9, $\mathrm{CuSO}_{4}$, sodium L-ascorbate, $\mathrm{DCM} / \mathrm{H}_{2} \mathrm{O}(1: 1, v / v)$; (b) 13, $\mathrm{CuSO}_{4}$, sodium L-ascorbate, DCM/H $\mathrm{H}_{2} \mathrm{O}(1: 1, v / v)$; (c) $\mathrm{MeONa} / \mathrm{MeOH}, 1 \mathrm{~h}$.

Alternatively, the 1-benzotriazolyl derivatives of pentacyclic triterpene 31-33 and 43 were coupled with intermediate 10 by route method in DMF. The crude products (compounds 34, 36, 38, and 44) were purified by column chromatography, and the coupling yields were good and ranged from $75 \%$ to $85 \%$ (Scheme 4). The Ac-removal of 34, 36, 38, and 44 under Zemplén conditions gave the corresponding conjugates 35, 37, 39, and 45, quantitatively. Similarly coupling 31-33 and 43 with 14 gave the final conjugates $40-42$ and 46 , respectively, with good yields ranging from $75 \%$ to $83 \%$.

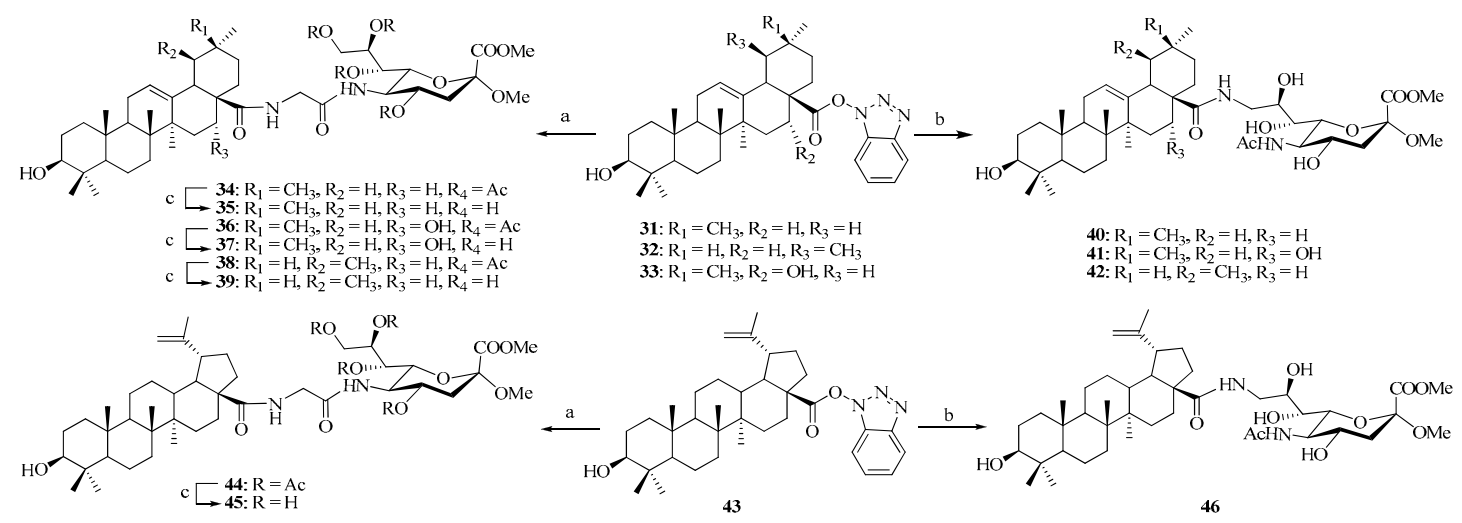

Scheme 4. Reagents and conditions: (a) 10, $\mathrm{Na}_{2} \mathrm{CO}_{3}, \mathrm{DMF}, 60^{\circ} \mathrm{C}, 24 \mathrm{~h}$; (b) $14, \mathrm{Na}_{2} \mathrm{CO}_{3}, \mathrm{DMF}, 60^{\circ} \mathrm{C}$, $24 \mathrm{~h}$; (c) $\mathrm{MeONa} / \mathrm{MeOH}, 1 \mathrm{~h}$.

All novel conjugates gave satisfactory analysis by TLC and ${ }^{1} \mathrm{H}$ - and ${ }^{13} \mathrm{C}-\mathrm{NMR}$ and HRMS. 


\subsection{Biological Evaluation}

Since the synthesis of sialic acid derivatives having a pentacyclic triterpene substituent at the C-5 or C-9 positions were accomplished, our attention was directed to the biological activities of the anti-influenza virus. Initially, we examined the cytotoxicity of the newly synthesized compounds 18-26, 28-30, 34-42, and 44-46 in Madin-Darby canine kidney (MDCK) cells using the CellTiter-Glo ${ }^{\circledR}$ assay. A culture medium containing $0.5 \%$ DMSO served as a negative control. 5-Fluorouracil (5-Fu) (a well-known broad spectrum anticancer drug [34]) was selected as a positive control. Except for compounds 26 and 42 (two sialic acid (C-9)-ursolic acid conjugates), the other compounds showed no significant cytotoxicity to MDCK cells at a concentration of $100 \mu \mathrm{M}$ (Figure 2).

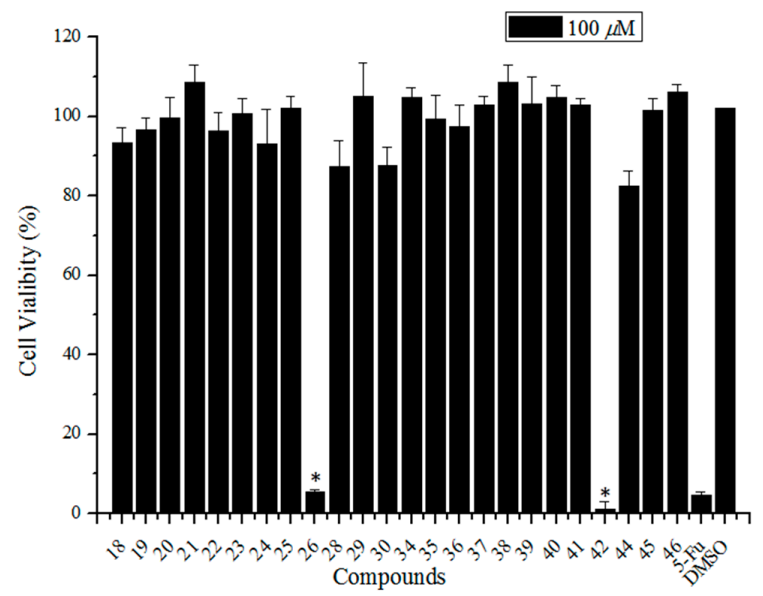

Figure 2. The cytotoxicity screening of sialic acid and pentacyclic triterpene conjugates $(100 \mu \mathrm{M})$ using CellTiter-Glo ${ }^{\circledR}$ Assay. DMSO and 5-Fu were used as negative and positive controls, respectively. Error bars indicate standard deviations of triplicate experiments. * compared with negative control, $p<0.05$.

The cytotoxicity of compounds $\mathbf{2 6}$ and $\mathbf{4 2}$ against human promyelocytic leukemia HL-60, human cervical cancer Hela, and human lung cancer A549, was further examined by the 3-(4,5-dimethylthiazol-2-yl)-2,5-diphenyltetrazolium bromide (MTT) assay with tested compound at a concentration of $0.1-10 \mu \mathrm{M}$ [35]. With the exception of compound 42, which showed weaker cytotoxicity against HL-60 $(10 \mu \mathrm{M}, 53 \%)$, no significant cytotoxicity was found (see Table S1 in Supplementary Materials). These results revealed that there was almost no cytotoxicity for those two ursolic acid-pentacyclic triterpene conjugates at a concentration of less than $10 \mu \mathrm{M}$.

Next, we examined the inhibitory activity of the test compounds against the virus replication in MDCK cells using the influenza A/WSN/33 (H1N1 subtype) virus strain at a concentration of $100 \mu \mathrm{M}$. The virus yields as a percent of control were estimated by a plaque titration method, and the results are shown in Figure 3 (including OSV and curcumin-a small-molecule entry inhibitor targeting the influenza virus HA1 domain [36] as positive controls). Four compounds 20, 28, 36, and 44 (two of them are echinocystic acid-sialic acid (C-5)-echinocystic acid conjugates 20 and 36 and the other two are sialic acid (C-5)-betulinic acid conjugates) showed weak anti-influenza A/WSN/33 virus activity with $\mathrm{IC}_{50}>100 \mu \mathrm{M}$. All the other compounds displayed no activity against influenza at high concentration. These data indicated that (1) the modification of the C-5 position of sialic acid showed a little more potent antiviral activity than the C-9 position; and (2) the introduction of large hydrophobic pentacyclic triterpene groups onto the C-5 acetamide or C-9 hydroxy of sialic acid might affect the interaction of sialic acid with HA during viral entry. The results of both the study described here and those previously reported by ours $[25,26]$ demonstrated that the C- 5 and C-9 positions of sialic acid were important for its binding with the HA protein (the introduction of a large hydrophobic group at those positions would affect their interaction), while the introduction of an appropriate hydrophobic 
group at the C-2 and C-4 positions of sialic acid could increase the binding with the active site of HA without detriment to binding affinity.

In order to determine their specificity for influenza virus infections, we further tested their inhibition activity on vesicular stomtatis virus G protein pseudo-particle (VSVpp), a negative-strand RNA virus with abroad host range that infects almost all cell lines. The results showed that they displayed no inhibition activity on VSV entry, indicating that they are specific anti-influenza entry inhibitors.

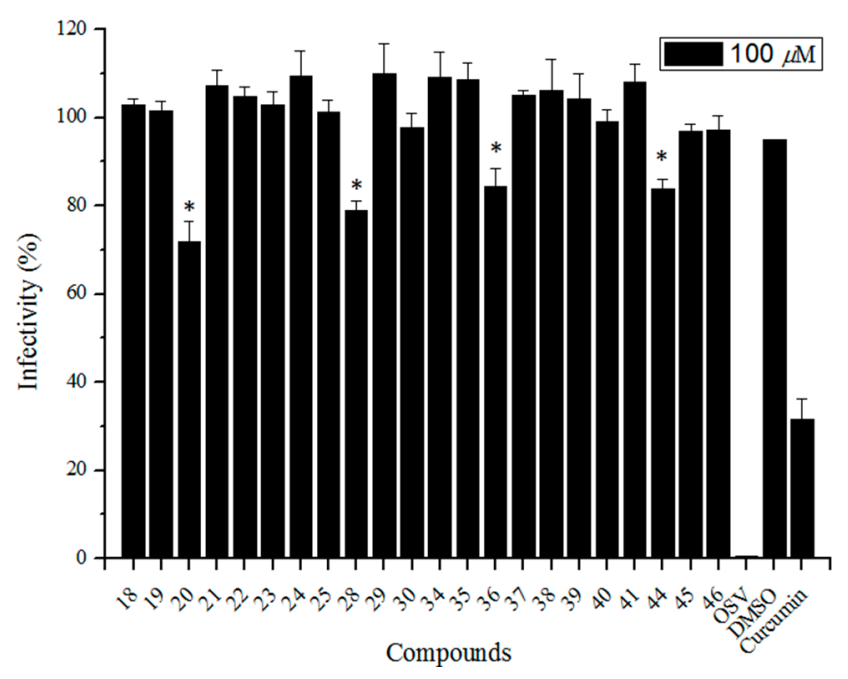

Figure 3. The cytopathic effect-based screening of conjugated sialic acid and pentacyclic triterpene derivatives. The Madin-Darby canine kidney (MDCK) was utilized as the host cell to test the A/WSN/33 virus infection; 0.5\% DMSO (final concentration) was used as the negative control; curcumin (a small-molecule entry inhibitor targeting the HA1 domain) as well as OSV (oseltamivir) were utilized as positive controls. Error bars indicate standard deviations of triplicate experiments. * compared with negative control, $p<0.05$.

In our previous study, we found that certain pentacyclic triterpene displayed broad spectrum anti-influenza activity by blocking virus entry. The synergistic effect of compound $\mathbf{2 0}$ (the most potent of the four compounds), combined with OSV (an oral neuraminidase inhibitor), was investigated to explore the potential of the compound for use in cocktail therapy. We found that the addition of compound 20 to OSV increased its efficacy at inhibiting influenza infection. According to the median-effect equation, [37] moderate synergic anti-influenza effects were observed with the combination index at 0.83 . The synergistic effect of pentacyclic triterpene with other anti-influenza virus inhibitors may provide a new option for the treatment of influenza virus infections.

\section{Materials and Methods}

\subsection{Chemistry}

High-resolution mass spectra (HRMS) were obtained with an APEX IV FT_MS (7.0T) spectrometer (Bruker Daltonics, Inc., Billerica, MA, USA) in positive ESI mode. NMR spectra were recorded on a Bruker DRX 400 spectrometer at ambient temperature. ${ }^{1} \mathrm{H}-\mathrm{NMR}$ chemical shifts were referenced to the internal standard TMS $\left(\delta_{\mathrm{H}}=0.00\right)$ or the solvent signal $\left(\delta_{\mathrm{H}}=3.31\right.$ for the central line of $\left.\mathrm{CD}_{3} \mathrm{OD}\right) \cdot{ }^{13} \mathrm{C}-\mathrm{NMR}$ chemical shifts were referenced to the solvent signal $\left(\delta_{\mathrm{C}}=77.00\right.$ for the central line of $\mathrm{CDCl}_{3}, \delta_{\mathrm{C}}=49.00$ for the central line of $\mathrm{CD}_{3} \mathrm{OD}$ ). Reactions were monitored by thin-layer chromatography (TLC) on a pre-coated silica gel $60 \mathrm{~F}_{254}$ plate (layer thickness $0.2 \mathrm{~mm}$; E. Merck, Darmstadt, Germany) and detected by staining with a yellow solution containing $\mathrm{Ce}\left(\mathrm{NH}_{4}\right)_{2}\left(\mathrm{NO}_{3}\right)_{6}$ $(0.5 \mathrm{~g})$ and $\left(\mathrm{NH}_{4}\right)_{6} \mathrm{Mo}_{7} \mathrm{O}_{24} \cdot 4 \mathrm{H}_{2} \mathrm{O}(24.0 \mathrm{~g})$ in $6 \% \mathrm{H}_{2} \mathrm{SO}_{4}(500 \mathrm{~mL})$, followed by heating. Flash column 
chromatography was performed on silica gel 60 (200-300 mesh, Qingdao Marine Chemical Co., Ltd., Qingdao, China).

All chemicals were used as supplied without further purification. The synthesis of compounds $\mathbf{2 - 8}, \mathbf{1 1}-\mathbf{1 7}, \mathbf{2 7}, \mathbf{3 1 - 3 3}$, and $\mathbf{4 3}$ has been reported previously [31,32,38]. The intermediates $\mathbf{9}$ and $\mathbf{1 0}$ and the novel sialic acid (C-5 or C-9)-pentacyclic triterpene-Neu5Ac2en conjugates 18-26, 28-30, 34-42, and $\mathbf{4 4 - 4 6}$ were obtained as follows.

\subsubsection{General Procedure A for the Click Reaction}

$\mathrm{CuSO}_{4}(48 \mathrm{mg}, 0.30 \mathrm{mmol})$ and sodium ascorbate $(119 \mathrm{mg}, 0.60 \mathrm{mmol})$ were added to a solution of alkyne $(0.45 \mathrm{mmol})$ and azide $(0.30 \mathrm{mmol})$ in $\mathrm{DCM} / \mathrm{H}_{2} \mathrm{O}(1: 1 \mathrm{v} / v, 12 \mathrm{~mL})$. The resulting solution was vigorously stirred at room temperature for $12 \mathrm{~h}$. The reaction mixture was extracted with DCM $(3 \times 10 \mathrm{~mL})$. The combined organic layer was dried over $\mathrm{Na}_{2} \mathrm{SO}_{4}$, filtered and concentrated. The residue was purified by column chromatography over silica gel.

\subsubsection{General Procedure B for the Deacetylation Reaction}

The per-O-acetylated sialic acid (C-5 or C-9)-pentacyclic triterpene conjugate was dissolved in dry $\mathrm{MeOH}\left(\sim 5 \mathrm{~mL}\right.$ per $100 \mathrm{mg}$ compound), and a solution of $\mathrm{MeONa}\left(30 \%\right.$ in $\mathrm{MeOH}, 0.1$ equiv mol ${ }^{-1}$ acetate) was added. The solution was stirred at room temperature for $3 \mathrm{~h}$. After completion (TLC), the reaction mixture was neutralized with Amberlite IR-120 $\left(\mathrm{H}^{+}\right)$ion-exchange resin, filtered, and concentrated. The crude product was purified by column chromatography over silica gel.

\subsubsection{General Procedure C for the Amidation Reaction}

$\mathrm{Na}_{2} \mathrm{CO}_{3}$ (201 mg, $1.9 \mathrm{mmol}$ ) was added to a solution of amino substituted sialic acid derivatives 10 or $14(0.37 \mathrm{mmol})$ and 1-benzotriazolyl activated pentacyclic triterpene $31-33$ or $\mathbf{4 3}(0.56 \mathrm{mmol})$ in DMF $(20 \mathrm{~mL})$. The resulting solution was vigorously stirred for $24 \mathrm{~h}$ at $60^{\circ} \mathrm{C}$. After completion (TLC), the reaction mixture was concentrated. The residue was purified by column chromatography over silica gel.

Methyl (O-methyl-5-(N-azidoacetyl)-4,7,8,9-tetra-O-acetyl-3,5-dideoxy-D-glycero- $\alpha$-D-galacto-2-nonulopyranosyl) onate (9). EDC (62 mg, $0.32 \mathrm{mmol}$ ) was added to a solution of 2-azidoacetic acid ( $33 \mathrm{mg}, 0.32 \mathrm{mmol}$ ) in dry THF. The resulting solution was vigorously stirred for $0.5 \mathrm{~h}$ at room temperature. Then compound $8(100 \mathrm{mg}, 0.22 \mathrm{mmol}$ - dissolved in dry THF $(10 \mathrm{~mL}))$ was added. The solution was stirred at room temperature for another $24 \mathrm{~h}$. After completion (TLC), the reaction mixture was concentrated, and the crude product was purified by column chromatography (eluent: $\mathrm{PE} / \mathrm{Act}=3: 2$ ) over silica gel to afford compound 9 as a white solid in $87 \%$ yield. $R_{\mathrm{f}}=0.25(\mathrm{PE} / \mathrm{Act}=2: 1) ;{ }^{1} \mathrm{H}-\mathrm{NMR}\left(400 \mathrm{MHz}, \mathrm{CDCl}_{3}\right): \delta$ $6.18(\mathrm{~d}, 1 \mathrm{H}, J=10.2 \mathrm{~Hz}), 5.42-5.47(\mathrm{~m}, 1 \mathrm{H}), 5.34(\mathrm{dd}, 1 \mathrm{H}, J=2.3,8.6 \mathrm{~Hz}), 4.91(\mathrm{ddd}, 1 \mathrm{H}, J=12.2,10.3$, $4.6 \mathrm{~Hz}), 4.31(\mathrm{dd}, 1 \mathrm{H}, J=2.6,12.5 \mathrm{~Hz}), 4.21(\mathrm{dd}, 1 \mathrm{H}, J=2.3,10.7 \mathrm{~Hz}), 4.03-4.14(\mathrm{~m}, 2 \mathrm{H}), 3.81-3.92(\mathrm{~m}$, $5 \mathrm{H}), 3.33(\mathrm{~s}, 3 \mathrm{H}), 2.61(\mathrm{dd}, 1 \mathrm{H}, J=4.7,12.8 \mathrm{~Hz}), 2.18,2.13,2.04,2.03\left(\mathrm{~s}, 3 \mathrm{H}\right.$ each, $\left.4 \times \mathrm{CH}_{3} \mathrm{CO}\right), 1.94(\mathrm{t}$, $1 \mathrm{H}, J=12.6 \mathrm{~Hz}) ;{ }^{13} \mathrm{C}-\mathrm{NMR}\left(100 \mathrm{MHz}, \mathrm{CDCl}_{3}\right): \delta 170.78,170.26,170.19,168.12,167.39,99.05,72.29$, $68.92,68.58,67.24,62.21,52.84,52.65,52.51,49.30,37.96,21.15,20.88,20.86,20.78$; ESI-HRMS calcd. for $\mathrm{C}_{21} \mathrm{H}_{30} \mathrm{NaN}_{4} \mathrm{O}_{13}[\mathrm{M}+\mathrm{H}]^{+}: 569.1702$, found 569.1708.

Methyl (O-methyl-5-(N-aminoacetyl)-4,7,8,9-tetra-O-acetyl-3,5-dideoxy-D-glycero- $\alpha$-D-galacto-2-nonulopyranosyl) onate (10). The compound 9 (230 mg, $0.42 \mathrm{mmol})$ was dissolved in $\mathrm{MeOH}(15 \mathrm{~mL})$, and palladium-carbon ( 0.1 equiv.) was added. The suspension was degassed under vacuum and urged with $\mathrm{H}_{2}$ three times; then it was stirred under an $\mathrm{H}_{2}$ balloon at room temperature for $24 \mathrm{~h}$. The suspension was filtered through a pad of celite and the pad cake was washed with $\mathrm{CH}_{3} \mathrm{OH}$. The combined filtrate was concentrated to dryness. The residue was used without further purification in the next step. 
Methyl (O-methyl-5-(N-(4-(N-(3ß-hydroxy-olean-12-en-28-oyl)-amino)methyl)-1H-1,2,3-triazolyl)acetyl -4,7,8,9-tetra-O-acetyl-3,5-dideoxy-D-glycero- $\alpha$-D-galacto-2-nonulopyranosyl)onate (18). Prepared from 9 and 15 according to general procedure A, the residue was purified by chromatography (eluent: $\mathrm{PE} /$ Act $=1: 1$ ) over silica gel to afford compound 18 as a white solid in 93\% yield. $R_{\mathrm{f}}=0.25$ $(\mathrm{PE} / \mathrm{Act}=1: 1) ;{ }^{1} \mathrm{H}-\mathrm{NMR}\left(400 \mathrm{MHz}, \mathrm{CDCl}_{3}\right): \delta 7.70(\mathrm{~s}, 1 \mathrm{H}), 6.66(\mathrm{t}, 1 \mathrm{H}, J=5.4 \mathrm{~Hz}), 6.45(\mathrm{~d}, 1 \mathrm{H}$, $J=9.8 \mathrm{~Hz}), 5.37-5.42(\mathrm{~m}, 2 \mathrm{H}), 5.28-5.31$ (m, 1H, overlap with DCM), $4.98(\mathrm{~d}, 1 \mathrm{H}, J=16.2 \mathrm{~Hz}), 4.75-4.82$ $(\mathrm{m}, 2 \mathrm{H}), 4.60(\mathrm{dd}, 1 \mathrm{H}, J=5.7,15.0 \mathrm{~Hz}), 4.24-4.34(\mathrm{~m}, 2 \mathrm{H}), 4.00-4.15(\mathrm{~m}, 3 \mathrm{H}), 3.75(\mathrm{~s}, 3 \mathrm{H}), 3.29(\mathrm{~s}$, $3 \mathrm{H}), 3.18-3.22(\mathrm{~m}, 1 \mathrm{H}), 2.55(\mathrm{dd}, 1 \mathrm{H}, \mathrm{J}=4.6,12.8 \mathrm{~Hz}), 2.13,2.10,2.03,1.94\left(\mathrm{~s}, 3 \mathrm{H}\right.$ each, $\left.4 \times \mathrm{CH}_{3} \mathrm{CO}\right)$, 2.01-0.93 (m, other aliphatic ring protons), 1.13, 0.97, 0.87, 0.86, 0.85, $0.76\left(\mathrm{~s}, 3 \mathrm{H}\right.$ each, $\left.6 \times \mathrm{CH}_{3}\right), 0.70$ $(\mathrm{d}, 1 \mathrm{H}, J=11.2 \mathrm{~Hz}), 0.60\left(\mathrm{~s}, 3 \mathrm{H}, \mathrm{CH}_{3}\right) ;{ }^{13} \mathrm{C}-\mathrm{NMR}\left(100 \mathrm{MHz}, \mathrm{CDCl}_{3}\right): \delta 178.51,170.79,170.72,170.53$, $170.23,168.07,165.72,145.39,144.47,124.37,123.25,99.11,79.06,72.28,68.74,67.42,62.38,55.20,52.85$, 52.76, 52.56, 49.71, 47.65, 46.74, 46.31, 42.04, 39.46, 38.84, 38.57, 37.98, 37.05, 35.06, 34.19, 33.09, 32.57, 32.42 , 30.80, 28.22, 27.39, 27.26, 25.91, 23.96, 23.71, 23.58, 21.24, 20.96, 20.91, 18.39, 16.69, 15.73, 15.48; ESI-HRMS calcd. for $\mathrm{C}_{54} \mathrm{H}_{82} \mathrm{~N}_{5} \mathrm{O}_{15}[\mathrm{M}+\mathrm{H}]^{+}:$1040.5802, found 1040.5798 .

Methyl (O-methyl-5-(N-(4-(N-(3ß-hydroxy-olean-12-en-28-oyl)-amino)methyl)-1H-1,2,3-triazolyl)acetyl-3,5 -dideoxy-D-glycero- $\alpha$-D-galacto-2-nonulopyranosyl)onate (19). Prepared from 18 according to general procedure $\mathrm{B}$, the residue was purified by chromatography (eluent: $\mathrm{DCM} / \mathrm{MeOH}=10: 1$ ) over silica gel to afford compound 19 as a white solid in $83 \%$ yield. $R_{\mathrm{f}}=0.24(\mathrm{DCM} / \mathrm{MeOH}=10: 1) ;{ }^{1} \mathrm{H}-\mathrm{NMR}$ (400 MHz, CD $3 \mathrm{OD}): \delta 7.85(\mathrm{~s}, 1 \mathrm{H}), 7.73(\mathrm{t}, 1 \mathrm{H}, J=5.3 \mathrm{~Hz}), 5.35$ (brs, 1H), $5.17(\mathrm{~s}, 2 \mathrm{H}), 4.40(\mathrm{dq}, 2 \mathrm{H}$, $J=5.5,15.1 \mathrm{~Hz}), 3.81-3.86(\mathrm{~m}, 6 \mathrm{H}), 3.63-3.72(\mathrm{~m}, 3 \mathrm{H}), 3.54(\mathrm{~d}, 1 \mathrm{H}, J=9.1 \mathrm{~Hz}), 3.34(\mathrm{~s}, 3 \mathrm{H}), 3.14(\mathrm{dd}$, $1 \mathrm{H}, J=4.4,11.2 \mathrm{~Hz}), 2.79(\mathrm{~d}, 1 \mathrm{H}, J=10.1 \mathrm{~Hz}), 2.66(\mathrm{dd}, 1 \mathrm{H}, J=4.6,12.8 \mathrm{~Hz}), 2.06(\mathrm{dt}, 1 \mathrm{H}, J=2.8$, 13.0 Hz), 1.88-1.89 (m, 2H), 1.00-1.81 (m, other aliphatic ring protons), 1.16, 0.97, 0.94, (s, 3H each, $\left.3 \times \mathrm{CH}_{3}\right), 0.92\left(\mathrm{~s}, 6 \mathrm{H}, 2 \times \mathrm{CH}_{3}\right), 0.78\left(\mathrm{~s}, 3 \mathrm{H}, \mathrm{CH}_{3}\right), 0.73(\mathrm{~d}, 1 \mathrm{H}, J=11.2 \mathrm{~Hz}), 0.56\left(\mathrm{~s}, 3 \mathrm{H}, \mathrm{CH}_{3}\right) ;{ }^{13} \mathrm{C}-\mathrm{NMR}$ (100 MHz, CD 3 OD): $\delta$ 180.24, 170.71, 169.14, 146.16, 145.01, 126.17, 124.14, 100.27, 79.58, 74.42, 72.49, $70.05,68.62,64.71,56.65,53.94,53.34,52.95,52.02,48.94,47.60,47.41,42.80,42.53,41.29,40.55,39.79$, $38.07,35.88,35.05,34.07,33.72,33.61,31.59,28.78,28.43,27.81,26.55,24.49,24.08,19.45,17.46,16.38$, 15.97; ESI-HRMS calcd. for $\mathrm{C}_{46} \mathrm{H}_{73} \mathrm{~N}_{5} \mathrm{NaO}_{11}[\mathrm{M}+\mathrm{Na}]^{+}$: 894.5199, found 894.5206.

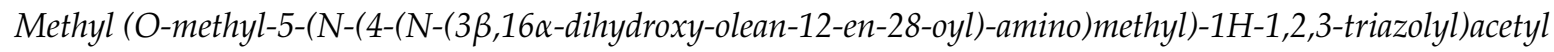
-4,7,8,9-tetra-O-acetyl-3,5-dideoxy-D-glycero- $\alpha$-D-galacto-2-nonulopyranosyl)onate (20). Prepared from 9 and $\mathbf{1 6}$ according to general procedure $\mathrm{A}$, the residue was purified by chromatography (eluent: $\mathrm{PE} /$ Act $=1: 1$ ) over silica gel to afford compound 20 as a white solid in 91\% yield. $R_{\mathrm{f}}=0.22$ $(\mathrm{PE} / \mathrm{Act}=1: 1) ;{ }^{1} \mathrm{H}-\mathrm{NMR}\left(400 \mathrm{MHz}, \mathrm{CDCl}_{3}\right): \delta 7.73(\mathrm{~s}, 1 \mathrm{H}), 6.94-6.97$ (m, 2H), 5.53 (brs, 1H), 5.39-5.44 $(\mathrm{m}, 1 \mathrm{H}), 5.34(\mathrm{dd}, 1 \mathrm{H}, J=3.1,8.0 \mathrm{~Hz}), 4.92(\mathrm{~d}, 1 \mathrm{H}, J=16.3 \mathrm{~Hz}), 4.80(\mathrm{dt}, 1 \mathrm{H}, J=4.5,12.0 \mathrm{~Hz}), 4.71(\mathrm{~d}$, $1 \mathrm{H}, J=16.3 \mathrm{~Hz}), 4.59(\mathrm{dd}, 1 \mathrm{H}, J=5.7,15.0 \mathrm{~Hz}), 4.34-4.38(\mathrm{~m}, 2 \mathrm{H}), 4.23(\mathrm{dd}, 1 \mathrm{H}, J=5.0,15.0 \mathrm{~Hz}), 4.17$ $(\mathrm{dd}, 1 \mathrm{H}, J=2.0,10.7 \mathrm{~Hz}), 4.03-4.12(\mathrm{~m}, 2 \mathrm{H}), 3.79(\mathrm{~s}, 3 \mathrm{H}), 3.30(\mathrm{~s}, 3 \mathrm{H}), 3.20-3.22(\mathrm{~m}, 1 \mathrm{H}), 2.73(\mathrm{dd}, 1 \mathrm{H}$, $J=3.1,13.4 \mathrm{~Hz}), 2.56(\mathrm{dd}, 1 \mathrm{H}, J=4.6,12.8 \mathrm{~Hz}), 2.52(\mathrm{~d}, 1 \mathrm{H}, J=4.6 \mathrm{~Hz}), 2.25(\mathrm{t}, 1 \mathrm{H}, J=13.2 \mathrm{~Hz}), 2.12$, $2.09,2.02,1.95\left(\mathrm{~s}, 3 \mathrm{H}\right.$ each, $\left.4 \times \mathrm{CH}_{3} \mathrm{CO}\right), 1.36,0.98\left(\mathrm{~s}, 3 \mathrm{H}\right.$ each, $\left.2 \times \mathrm{CH}_{3}\right), 1.00-2.07$ (m, other aliphatic ring protons), $0.89\left(\mathrm{~s}, 9 \mathrm{H}, 3 \times \mathrm{CH}_{3}\right), 0.77\left(\mathrm{~s}, 3 \mathrm{H}, \mathrm{CH}_{3}\right), 0.73(\mathrm{~d}, 1 \mathrm{H}, J=11.5 \mathrm{~Hz}), 0.69\left(\mathrm{~s}, 3 \mathrm{H}, \mathrm{CH}_{3}\right)$; ${ }^{13} \mathrm{C}-\mathrm{NMR}\left(100 \mathrm{MHz}, \mathrm{CDCl}_{3}\right): \delta 178.42,170.90,170.74,170.70,170.18,168.25,165.88,144.96,143.77$, $124.22,123.66,99.19,79.02,75.61,72.45,68.88,68.80,67.67,62.51,55.31,52.91,52.60,52.52,49.60,49.10$, $47.06,46.83,41.89,41.57,39.70,38.88,38.69,38.10,37.07,35.41,35.29,35.06,32.73,32.59,30.38,29.86$, 28.21, 27.31, 26.89, 25.10, 23.51, 21.26, 20.97, 20.94, 20.89, 18.37, 16.88, 15.75, 15.72; ESI-HRMS calcd. for $\mathrm{C}_{54} \mathrm{H}_{81} \mathrm{~N}_{5} \mathrm{NaO}_{16}[\mathrm{M}+\mathrm{Na}]^{+}: 1078.5571$, found 1078.5580 .

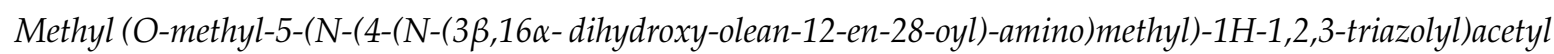
-3,5-dideoxy-D-glycero- $\alpha$-D-galacto-2-nonulopyranosyl)onate (21). Prepared from 20 according to general procedure $B$, the residue was purified by chromatography (eluent: $\mathrm{DCM} / \mathrm{MeOH}=10: 1$ ) over silica gel to afford compound 21 as a white solid in $87 \%$ yield. $R_{\mathrm{f}}=0.21(\mathrm{DCM} / \mathrm{MeOH}=10: 1) ;{ }^{1} \mathrm{H}-\mathrm{NMR}$ (400 MHz, CD $3 \mathrm{OD}): \delta 7.84(\mathrm{~s}, 1 \mathrm{H}), 7.56(\mathrm{t}, 1 \mathrm{H}, J=5.3 \mathrm{~Hz}), 5.46$ (brs, 1H), $5.17(\mathrm{~s}, 2 \mathrm{H}), 4.31-4.43(\mathrm{~m}, 3 \mathrm{H})$, 3.81-3.87 (m, 6H), 3.62-3.71 (m, 3H), $3.53(\mathrm{~d}, 1 \mathrm{H}, J=9.1 \mathrm{~Hz}), 3.34(\mathrm{~s}, 3 \mathrm{H}), 3.15(\mathrm{dd}, 1 \mathrm{H}, J=5.0,11.1 \mathrm{~Hz})$, 
$2.86(\mathrm{dd}, 1 \mathrm{H}, J=3.6,13.6 \mathrm{~Hz}), 2.66(\mathrm{dd}, 1 \mathrm{H}, J=4.7,12.8 \mathrm{~Hz}), 2.36(\mathrm{t}, 1 \mathrm{H}, J=13.2 \mathrm{~Hz}), 1.89-1.98(\mathrm{~m}, 4 \mathrm{H})$, $1.74(\mathrm{t}, 1 \mathrm{H}, J=12.3 \mathrm{~Hz}), 1.01-1.65(\mathrm{~m}$, other aliphatic ring protons), $1.37,0.97,0.96,0.92,0.88,0.78(\mathrm{~s}, 3 \mathrm{H}$ each, $\left.6 \times \mathrm{CH}_{3}\right), 0.74(\mathrm{~d}, 1 \mathrm{H}, J=11.2 \mathrm{~Hz}), 0.57\left(\mathrm{~s}, 3 \mathrm{H}, \mathrm{CH}_{3}\right) ;{ }^{13} \mathrm{C}-\mathrm{NMR}\left(100 \mathrm{MHz}, \mathrm{CD}_{3} \mathrm{OD}\right): \delta 180.11$, $170.75,169.16,145.96,144.93,126.07,124.25,100.30,79.63,75.63,74.47,72.51,70.08,68.66,64.75,56.76$, 53.96, 53.34, 52.96, 52.03, 49.90, 48.12, 48.06, 42.75, 42.30, 41.33, 40.71, 39.91, 39.82, 38.07, 36.37, 36.02, $35.95,33.89,33.31,31.97,31.24,28.73,27.87,27.30,25.33,24.46,19.44,17.54,16.36,16.17$; ESI-HRMS calcd. for $\mathrm{C}_{46} \mathrm{H}_{73} \mathrm{~N}_{5} \mathrm{NaO}_{12}[\mathrm{M}+\mathrm{Na}]^{+}:$: 910.5148 , found 910.5152 .

Methyl (O-methyl-5-(N-(4-(N-(3ß-hydroxy-urs-12-en-28-oyl)-amino)methyl)-1H-1,2,3-triazolyl)acetyl-4,7,8,9 -tetra-O-acetyl-3,5-dideoxy-D-glycero- $\alpha$-D-galacto-2-nonulopyranosyl)onate (22). Prepared from 9 and 17 according to general procedure $\mathrm{A}$, the residue was purified by chromatography (eluent: $\mathrm{PE} / \mathrm{Act}=1: 1$ ) over silica gel to afford compound 22 as a white solid in 95\% yield. $R_{\mathrm{f}}=0.25$ (PE/Act $=1: 1$ ); ${ }^{1} \mathrm{H}-\mathrm{NMR}$ $\left(400 \mathrm{MHz}, \mathrm{CDCl}_{3}\right): \delta 7.69(\mathrm{~s}, 1 \mathrm{H}), 6.67(\mathrm{t}, 1 \mathrm{H}, J=5.2 \mathrm{~Hz}), 6.58(\mathrm{~d}, 1 \mathrm{H}, J=9.8 \mathrm{~Hz}), 5.37-5.41(\mathrm{~m}, 1 \mathrm{H})$, $5.29-5.31(\mathrm{~m}, 2 \mathrm{H}), 4.97(\mathrm{~d}, 1 \mathrm{H}, J=16.2 \mathrm{~Hz}), 4.75-4.82(\mathrm{~m}, 2 \mathrm{H}), 4.58(\mathrm{dd}, 1 \mathrm{H}, J=5.8,15.0 \mathrm{~Hz}), 4.32(\mathrm{dd}$, $1 \mathrm{H}, J=2.5,12.4 \mathrm{~Hz}), 4.25(\mathrm{dd}, 1 \mathrm{H}, J=4.8,15.0 \mathrm{~Hz}), 4.00-4.15(\mathrm{~m}, 3 \mathrm{H}), 3.74(\mathrm{~s}, 3 \mathrm{H}), 3.28(\mathrm{~s}, 3 \mathrm{H}), 3.17-3.21$ $(\mathrm{m}, 1 \mathrm{H}), 2.55(\mathrm{dd}, 1 \mathrm{H}, J=4.7,12.8 \mathrm{~Hz}), 2.12,2.09,2.02,1.93\left(\mathrm{~s}, 3 \mathrm{H}\right.$ each, $\left.4 \times \mathrm{CH}_{3} \mathrm{CO}\right), 0.97-1.98(\mathrm{~m}$, other aliphatic ring protons), 1.06, 0.96, 0.91, $0.86\left(\mathrm{~s}, 3 \mathrm{H}\right.$ each, $\left.4 \times \mathrm{CH}_{3}\right), 0.83\left(\mathrm{~d}, 3 \mathrm{H}, J=6.4 \mathrm{~Hz}, \mathrm{CH}_{3}\right), 0.75(\mathrm{~s}$, $\left.3 \mathrm{H}, \mathrm{CH}_{3}\right), 0.69(\mathrm{~d}, 1 \mathrm{H}, J=11.8 \mathrm{~Hz}), 0.61\left(\mathrm{~s}, 3 \mathrm{H}, \mathrm{CH}_{3}\right) ;{ }^{13} \mathrm{C}-\mathrm{NMR}\left(100 \mathrm{MHz}, \mathrm{CDCl}_{3}\right): \delta 178.38,170.76$, $170.69,170.54,170.22,168.07,165.78,145.27,139.26,126.17,124.19,99.09,79.06,72.26,68.78,68.72,67.41$, $62.35,55.18,53.56,52.83,52.67,52.55,49.62,47.70,47.62,42.43,39.77,39.59,39.05,38.81,38.69,37.96$, $37.14,37.00,34.99,32.76,30.92,28.24,27.90,27.26,24.99,23.40,21.31,21.23,20.95,20.90,18.35,17.28$, 16.66, 15.78, 15.57; ESI-HRMS calcd. for $\mathrm{C}_{54} \mathrm{H}_{82} \mathrm{~N}_{5} \mathrm{O}_{15}[\mathrm{M}+\mathrm{H}]^{+}:$: 1040.5802, found 1040.5807.

Methyl (O-methyl-5-(N-(4-(N-(3ß-hydroxy-urs-12-en-28-oyl)-amino)methyl)-1H-1,2,3-triazolyl)acetyl-3,5dideoxy-D-glycero- $\alpha$-D-galacto-2-nonulopyranosyl)onate (23). Prepared from 22 according to general procedure $\mathrm{B}$, the residue was purified by chromatography (eluent: $\mathrm{DCM} / \mathrm{MeOH}=10: 1$ ) over silica gel to afford compound 22 as a white solid in $89 \%$ yield. $R_{\mathrm{f}}=0.25(\mathrm{DCM} / \mathrm{MeOH}=10: 1) ;{ }^{1} \mathrm{H}-\mathrm{NMR}$ $\left(400 \mathrm{MHz}, \mathrm{CD}_{3} \mathrm{OD}\right): \delta 7.84(\mathrm{~s}, 1 \mathrm{H}), 7.65(\mathrm{t}, 1 \mathrm{H}, J=5.4 \mathrm{~Hz}), 5.33(\mathrm{brs}, 1 \mathrm{H}), 5.16(\mathrm{~s}, 2 \mathrm{H}), 4.33-4.43(\mathrm{~m}, 2 \mathrm{H})$, 3.82-3.87 (m, 6H), 3.62-3.72 (m, 3H), $3.54(\mathrm{~d}, 1 \mathrm{H}, J=9.1 \mathrm{~Hz}), 3.34(\mathrm{~s}, 3 \mathrm{H}$, overlap with $\mathrm{MeOH}), 3.15$ $(\mathrm{dd}, 1 \mathrm{H}, J=4.9,11.0 \mathrm{~Hz}), 2.66(\mathrm{dd}, 1 \mathrm{H}, J=4.6,12.7 \mathrm{~Hz}), 2.14(\mathrm{~d}, 1 \mathrm{H}, J=10.7 \mathrm{~Hz}), 2.12(\mathrm{dt}, 1 \mathrm{H}, J=3.8$, $13.2 \mathrm{~Hz}), 1.90-1.91(\mathrm{~m}, 2 \mathrm{H}), 1.10-1.78\left(\mathrm{~m}\right.$, other aliphatic ring protons), $1.11\left(\mathrm{~s}, 3 \mathrm{H}, \mathrm{CH}_{3}\right), 0.97(\mathrm{~s}, 6 \mathrm{H}$, $\left.2 \times \mathrm{CH}_{3}\right), 0.93\left(\mathrm{~s}, 3 \mathrm{H}, \mathrm{CH}_{3}\right), 0.90\left(\mathrm{~d}, 3 \mathrm{H}, J=6.4 \mathrm{~Hz}, \mathrm{CH}_{3}\right), 0.78\left(\mathrm{~s}, 3 \mathrm{H}, \mathrm{CH}_{3}\right), 0.73(\mathrm{~d}, 1 \mathrm{H}, J=11.2 \mathrm{~Hz})$, 0.58 (s, 3H, $\left.\mathrm{CH}_{3}\right) ;{ }^{13} \mathrm{C}-\mathrm{NMR}\left(100 \mathrm{MHz}, \mathrm{CD}_{3} \mathrm{OD}\right): \delta 180.12,170.72,169.14,146.12,139.68,127.32,126.11$, 100.29, 79.59, 74.43, 72.51, 70.07, 68.65, 64.73, 56.64, 54.14, 53.95, 53.34, 52.98, 52.03, 48.91, 43.19, 41.31, $40.78,40.23,39.93,39.80,38.49,38.03,35.83,34.07,31.86,28.90,28.80,27.85,25.27,24.32,24.13,21.62$, 19.41, 17.76, 17.50, 16.43, 16.11; ESI-HRMS calcd. for $\mathrm{C}_{46} \mathrm{H}_{73} \mathrm{~N}_{5} \mathrm{NaO}_{11}[\mathrm{M}+\mathrm{Na}]^{+}$: 894.5199, found 894.5198 .

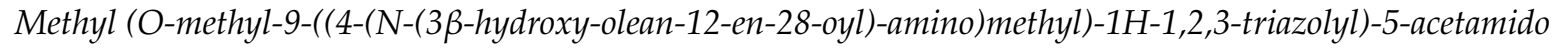
-3,5-dideoxy-D-glycero- $\alpha$-D-galacto-2-nonulopyranosyl)onate (24). Prepared from 13 and 15 according to general procedure $\mathrm{A}$, the residue was purified by column chromatography (eluent: $\mathrm{DCM} / \mathrm{MeOH}=$ 15:1) over silica gel to afford compound 24 as a white solid in $83 \%$ yield. $R_{\mathrm{f}}=0.29(\mathrm{DCM} / \mathrm{MeOH}$ $=12: 1) ;{ }^{1} \mathrm{H}-\mathrm{NMR}\left(400 \mathrm{MHz}, \mathrm{CD}_{3} \mathrm{OD}\right): \delta 7.79(\mathrm{~s}, 1 \mathrm{H}), 7.70(\mathrm{t}, 1 \mathrm{H}, J=5.5 \mathrm{~Hz}), 5.31(\mathrm{t}, 1 \mathrm{H}, J=2.9 \mathrm{~Hz})$, $4.78(\mathrm{dd}, 1 \mathrm{H}, J=2.4,14.1 \mathrm{~Hz}), 4.30-4.40(\mathrm{~m}, 3 \mathrm{H}), 4.10(\mathrm{dt}, 1 \mathrm{H}, J=2.2,8.4 \mathrm{~Hz}), 3.78(\mathrm{~s}, 3 \mathrm{H}), 3.73(\mathrm{t}, 1 \mathrm{H}$, $J=10.3 \mathrm{~Hz}), 3.54-3.63(\mathrm{~m}, 2 \mathrm{H}), 3.37-3.39(\mathrm{~m}, 1 \mathrm{H}), 3.10(\mathrm{dd}, 1 \mathrm{H}, J=4.5,10.7 \mathrm{~Hz}), 2.76(\mathrm{dd}, 1 \mathrm{H}, J=3.7$, $13.3 \mathrm{~Hz}), 2.60(\mathrm{dd}, 1 \mathrm{H}, J=4.5,12.7 \mathrm{~Hz}), 1.96(\mathrm{~s}, 3 \mathrm{H}), 0.68-2.05$ (m, other aliphatic ring protons), 1.12, 0.93, 0.91, 0.88, 0.87,0.74, 0.54 (s, 3H each, $\left.7 \times \mathrm{CH}_{3}\right) ;{ }^{13} \mathrm{C}-\mathrm{NMR}\left(100 \mathrm{MHz}, \mathrm{CD}_{3} \mathrm{OD}\right): \delta 180.41,175.20$, $170.72,145.08,125.68,124.22,100.41,79.67,74.68,71.61,71.33,68.41,56.69,54.79,53.82,53.35,52.11$, 47.60, 47.51, 42.87, 42.62, 41.39, 40.61, 39.83, 38.11, 35.98, 35.06, 34.14, 33.79, 33.54, 31.62, 28.73, 28.47, $27.85,26.44,24.52,24.03,22.68,19.46,17.54,16.34,16.16,15.93$; ESI-HRMS calcd. for $\mathrm{C}_{46} \mathrm{H}_{74} \mathrm{O}_{10} \mathrm{~N}_{5}$ $[\mathrm{M}+\mathrm{H}]^{+}:$856.5430, found 856.5415. 


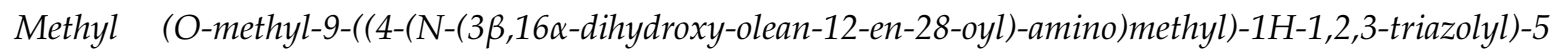
-acetamido-3,5-dideoxy-D-glycero- $\alpha$-D-galacto-2-nonulopyranosyl)onate (25). Prepared from 13 and 16 according to general procedure $\mathrm{A}$, the residue was purified by column chromatography (eluent: $\mathrm{DCM} / \mathrm{MeOH}=18: 1$ ) over silica gel to afford compound 25 as a white solid in $81 \%$ yield. $R_{\mathrm{f}}=0.27$ $(\mathrm{DCM} / \mathrm{MeOH}=12: 1) ;{ }^{1} \mathrm{H}-\mathrm{NMR}\left(400 \mathrm{MHz}, \mathrm{CD}_{3} \mathrm{OD}\right): \delta 7.78(\mathrm{~s}, 1 \mathrm{H}), 7.53(\mathrm{t}, 1 \mathrm{H}, J=5.3 \mathrm{~Hz}), 5.43(\mathrm{t}$, $1 \mathrm{H}, J=3.2 \mathrm{~Hz}), 4.82(\mathrm{dd}, 1 \mathrm{H}, J=2.4,14.0 \mathrm{~Hz}), 4.27-4.38(\mathrm{~m}, 4 \mathrm{H}), 4.11(\mathrm{dt}, 1 \mathrm{H}, J=2.4,8.4 \mathrm{~Hz}), 3.79$ $(\mathrm{s}, 3 \mathrm{H}), 3.74(\mathrm{t}, 1 \mathrm{H}, J=5.6 \mathrm{~Hz}), 3.54-3.63(\mathrm{~m}, 2 \mathrm{H}), 3.37(\mathrm{dd}, 1 \mathrm{H}, J=1.5,8.4 \mathrm{~Hz}), 3.11(\mathrm{dd}, 1 \mathrm{H}, J=5.1$, $11.7 \mathrm{~Hz}), 2.84(\mathrm{dd}, 1 \mathrm{H}, J=3.7,13.5 \mathrm{~Hz}), 2.60(\mathrm{dd}, 1 \mathrm{H}, J=4.6,12.7 \mathrm{~Hz}), 2.32(\mathrm{t}, 1 \mathrm{H}, J=13.7 \mathrm{~Hz}), 2.11(\mathrm{~s}$, $1 \mathrm{H}), 1.96(\mathrm{~s}, 3 \mathrm{H}), 0.91-1.98$ (m, other aliphatic ring protons), 1.13, 0.93, 0.92, 0.89, 0.85, 0.74 (s, 3H each, $\left.6 \times \mathrm{CH}_{3}\right), 0.74(\mathrm{~d}, 1 \mathrm{H}, \mathrm{J}=11.4 \mathrm{~Hz}), 0.56\left(\mathrm{~s}, 3 \mathrm{H}, \mathrm{CH}_{3}\right) ;{ }^{13} \mathrm{C}-\mathrm{NMR}\left(100 \mathrm{MHz}, \mathrm{CD}_{3} \mathrm{OD}\right): \delta 180.19,175.21$, $170.73,145.73,144.95,125.50,124.31,100.41,79.65,75.60,74.68,71.61,71.33,68.41,56.79,54.79,53.83$, 53.36, 52.12, 49.98, 48.16, 48.03, 42.81, 42.37, 41.38, 40.75, 39.93, 39.84, 38.09, 36.35, 36.12, 35.99, 33.96, $33.28,31.86,31.24,28.71,27.90,27.28,25.36,24.47,22.69,19.45,17.61,16.34,16.15$; ESI-HRMS calcd. for $\mathrm{C}_{46} \mathrm{H}_{74} \mathrm{O}_{11} \mathrm{~N}_{5}[\mathrm{M}+\mathrm{H}]^{+}:$872.5379, found 872.5360 .

Methyl

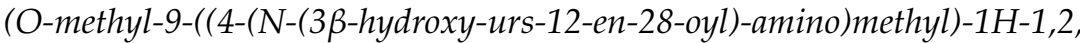
3-triazolyl)-5-acetamido-3,5 -dideoxy-D-glycero- $\alpha$-D-galacto-2-nonulopyranosyl)onate (26). Prepared from 13 and 17 according to general procedure $A$, the residue was purified by column chromatography (eluent: $\mathrm{DCM} / \mathrm{MeOH}=12: 1$ ) over silica gel to afford compound 26 as a white solid in $87 \%$ yield. $R_{\mathrm{f}}=$ $0.30(\mathrm{DCM} / \mathrm{MeOH}=12: 1) ;{ }^{1} \mathrm{H}-\mathrm{NMR}\left(400 \mathrm{MHz}, \mathrm{CD}_{3} \mathrm{OD}\right): \delta 7.78(\mathrm{~s}, 1 \mathrm{H}), 7.59(\mathrm{t}, 1 \mathrm{H}, J=4.9 \mathrm{~Hz}), 5.29$ (brs, $1 \mathrm{H}), 4.46-4.78\left(\mathrm{~m}, 1 \mathrm{H}\right.$, overlap with $\left.\mathrm{H}_{2} \mathrm{O}\right), 4.33-4.38(\mathrm{~m}, 3 \mathrm{H}), 4.11(\mathrm{dt}, 1 \mathrm{H}, J=1.6,8.1 \mathrm{~Hz}), 3.79$ $(\mathrm{s}, 3 \mathrm{H}), 3.73(\mathrm{t}, 1 \mathrm{H}, J=9.8 \mathrm{~Hz}), 3.54-3.63(\mathrm{~m}, 2 \mathrm{H}), 3.37(\mathrm{~d}, 1 \mathrm{H}, J=8.4 \mathrm{~Hz}), 3.11(\mathrm{dd}, 1 \mathrm{H}, J=4.9,11.4$ $\mathrm{Hz}), 2.60(\mathrm{dd}, 1 \mathrm{H}, J=4.6,12.7 \mathrm{~Hz}), 2.10(\mathrm{~d}, 1 \mathrm{H}, J=10.8 \mathrm{~Hz}), 2.03(\mathrm{dt}, 1 \mathrm{H}, J=3.4,12.2 \mathrm{~Hz}), 1.96(\mathrm{~s}, 3 \mathrm{H})$, 0.56-1.89 (m, other aliphatic ring protons), $1.07\left(\mathrm{~s}, 3 \mathrm{H}, \mathrm{CH}_{3}\right), 0.93\left(\mathrm{~s}, 6 \mathrm{H}, 2 \times \mathrm{CH}_{3}\right), 0.90\left(\mathrm{~s}, 3 \mathrm{H}, \mathrm{CH}_{3}\right)$, $0.86\left(\mathrm{~d}, 3 \mathrm{H}, J=6.3 \mathrm{~Hz}, \mathrm{CH}_{3}\right), 0.74\left(\mathrm{~s}, 3 \mathrm{H}, \mathrm{CH}_{3}\right), 0.69(\mathrm{~d}, 1 \mathrm{H}, J=11.4 \mathrm{~Hz}), 0.56\left(\mathrm{~s}, 3 \mathrm{H}, \mathrm{CH}_{3}\right) ;{ }^{13} \mathrm{C}-\mathrm{NMR}$ (100 MHz, CD 3 OD): $\delta$ 180.20, 180.12, 175.16, 170.71, 139.77, 127.36, 125.54, 100.39, 79.63, 74.67, 71.54, $71.3,68.38,56.67,54.76,54.22,53.82,53.35,52.11,48.36,43.25,41.37,40.81,40.28,39.96,39.82,38.53$, $38.06,35.94,35.83,34.13,31.88,28.92,28.78,27.89,25.28,24.34,24.09,22.7,21.59,19.42,17.72,17.57$; ESI-HRMS calcd. for $\mathrm{C}_{46} \mathrm{H}_{74} \mathrm{O}_{10} \mathrm{~N}_{5}[\mathrm{M}+\mathrm{H}]^{+}$: 856.5430, found 856.5412.

Methyl (O-methyl-5-(N-(4-(N-(3ß-hydroxy-lup-20(29)-en-28-oyl)-amino)methyl)-1H-1,2,3-triazolyl)acetyl -4,7,8,9-tetra-O-acetyl-3,5-dideoxy-D-glycero- $\alpha$-D-galacto-2-nonulopyranosyl)onate (28). Prepared from 9 and 27 according to general procedure $\mathrm{A}$, the residue was purified by chromatography (eluent: PE/Act $=1: 1)$ over silica gel to afford compound 28 as a white solid in $88 \%$ yield. $R_{\mathrm{f}}=0.27(\mathrm{PE} / \mathrm{Act}=1: 1)$; ${ }^{1} \mathrm{H}-\mathrm{NMR}\left(400 \mathrm{MHz}, \mathrm{CDCl}_{3}\right): \delta 7.71(\mathrm{~s}, 1 \mathrm{H}), 6.55(\mathrm{~d}, 1 \mathrm{H}, \mathrm{J}=9.9 \mathrm{~Hz}), 6.49(\mathrm{t}, 1 \mathrm{H}, J=5.5 \mathrm{~Hz}), 5.40(\mathrm{dt}, 1 \mathrm{H}$, $J=2.5,6.2 \mathrm{~Hz}), 5.30(\mathrm{dd}, 1 \mathrm{H}, J=2.1,7.7 \mathrm{~Hz}), 5.03(\mathrm{~d}, 1 \mathrm{H}, J=16.1 \mathrm{~Hz}), 4.77-4.83(\mathrm{~m}, \mathrm{H}), 4.78(\mathrm{~d}, 1 \mathrm{H}$, $J=16.0 \mathrm{~Hz}), 4.71$ (brs, 1H), 4.56 (brs, $1 \mathrm{H}), 4.51(\mathrm{dd}, 1 \mathrm{H}, \mathrm{J}=5.5,15.0 \mathrm{~Hz}), 4.40(\mathrm{dd}, 1 \mathrm{H}, J=5.5,15.0 \mathrm{~Hz})$, $4.35(\mathrm{dd}, 1 \mathrm{H}, \mathrm{J}=2.5,12.4 \mathrm{~Hz}), 4.00-4.17(\mathrm{~m}, 3 \mathrm{H}), 3.73(\mathrm{~s}, 3 \mathrm{H}), 3.29(\mathrm{~s}, 3 \mathrm{H}), 3.14-3.20(\mathrm{~m}, 1 \mathrm{H}), 3.09(\mathrm{dt}$, $1 \mathrm{H}, J=3.9,11.2 \mathrm{~Hz}), 2.55(\mathrm{dd}, 1 \mathrm{H}, J=4.7,12.8 \mathrm{~Hz}), 2.39(\mathrm{dt}, 1 \mathrm{H}, J=3.3,12.8 \mathrm{~Hz}), 2.13,2.10,2.04,1.93(\mathrm{~s}$, $3 \mathrm{H}$ each, $\left.4 \times \mathrm{CH}_{3} \mathrm{CO}\right), 0.84-1.95$ (m, other aliphatic ring protons), 1.65, 0.94, 0.92, 0.79, 0.77, 0.74 (s, $3 \mathrm{H}$ each, $\left.6 \times \mathrm{CH}_{3}\right), 0.64(\mathrm{~d}, 1 \mathrm{H}, J=8.7 \mathrm{~Hz}) ;{ }^{13} \mathrm{C}-\mathrm{NMR}\left(100 \mathrm{MHz}, \mathrm{CDCl}_{3}\right): \delta 176.55,170.83,170.73,170.52$, $170.31,168.07,165.71,150.97,145.92,124.29,109.50,99.11,79.10,72.31,68.96,68.73,67.49,62.42,55.66$, $55.45,52.88,52.82,52.54,50.70,50.26,49.66,46.80,42.53,40.86,38.94,38.82,38.31,37.91,37.77,37.30$, $34.79,34.43,33.59,30.96,29.50,28.12,27.50,25.70,21.24,21.08,20.98,20.92,19.57,18.41,16.30,15.90$, 15.56, 14.74; ESI-HRMS calcd. for $\mathrm{C}_{54} \mathrm{H}_{82} \mathrm{~N}_{5} \mathrm{O}_{15}[\mathrm{M}+\mathrm{H}]^{+}:$: 1040.5802, found 1040.5809 .

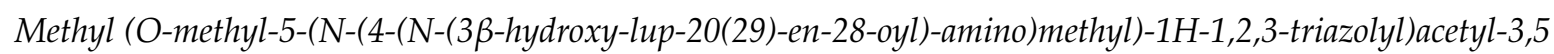
-dideoxy-D-glycero- $\alpha$-D-galacto-2-nonulopyranosyl)onate (29). Prepared from 28 according to general procedure $\mathrm{B}$, the residue was purified by chromatography (eluent: $\mathrm{DCM} / \mathrm{MeOH}=10: 1$ ) over silica gel to afford compound 29 as a white solid in $78 \%$ yield. $R_{\mathrm{f}}=0.26(\mathrm{DCM} / \mathrm{MeOH}=10: 1) ;{ }^{1} \mathrm{H}-\mathrm{NMR}$ (400 MHz, CD $3 \mathrm{OD}): \delta 8.07(\mathrm{t}, 1 \mathrm{H}, J=5.6 \mathrm{~Hz}), 7.86(\mathrm{~s}, 1 \mathrm{H}), 5.19(\mathrm{~d}, 1 \mathrm{H}, J=16.0 \mathrm{~Hz}), 5.15(\mathrm{~d}, 1 \mathrm{H}$, $J=16.0 \mathrm{~Hz}), 4.70$ (brs, $1 \mathrm{H}), 4.58$ (brs, $1 \mathrm{H}), 4.41(\mathrm{dq}, 2 \mathrm{H}, J=5.5,15.1 \mathrm{~Hz}), 3.80-3.87(\mathrm{~m}, 6 \mathrm{H}), 3.62-3.73$ 
$(\mathrm{m}, 3 \mathrm{H}), 3.53(\mathrm{~d}, 1 \mathrm{H}, J=9.3 \mathrm{~Hz}), 3.34(\mathrm{~s}, 3 \mathrm{H}), 3.05-3.14(\mathrm{~m}, 2 \mathrm{H}), 2.66(\mathrm{dd}, 1 \mathrm{H}, J=4.6,12.8 \mathrm{~Hz}), 2.53(\mathrm{dt}$, $1 \mathrm{H}, J=3.1,13.0 \mathrm{~Hz}), 2.13(\mathrm{brd}, 1 \mathrm{H}, J=13.4 \mathrm{~Hz}), 0.92-1.92(\mathrm{~m}$, other aliphatic ring protons), 1.68, 0.98 , $0.95\left(\mathrm{~s}, 3 \mathrm{H}\right.$ each, $\left.3 \times \mathrm{CH}_{3}\right), 0.85\left(\mathrm{~s}, 6 \mathrm{H}, 2 \times \mathrm{CH}_{3}\right), 0.76\left(\mathrm{~s}, 3 \mathrm{H}, \mathrm{CH}_{3}\right), 0.69(\mathrm{~d}, 1 \mathrm{H}, J=9.1 \mathrm{~Hz}) ;{ }^{13} \mathrm{C}-\mathrm{NMR}$ (100 MHz, CD $\mathrm{CD}_{3} \mathrm{OD}$ ): $\delta$ 179.15, 170.78, 169.22, 152.29, 146.84, 125.99, 109.97, 100.33, 79.66, 74.51, 72.54, $70.14,68.64,64.78,56.93,54.03,53.32,52.99,52.09,52.02,51.44,48.08,43.49,42.01,41.36,40.11,39.95$, $39.19,38.92,38.33,35.55,34.04,31.93,30.54,28.64,28.05,26.99,22.15,19.68,19.50,16.82,16.63,16.17$, 15.10; ESI-HRMS calcd. for $\mathrm{C}_{46} \mathrm{H}_{74} \mathrm{~N}_{5} \mathrm{O}_{11}[\mathrm{M}+\mathrm{H}]^{+}$: 872.5379, found 872.5385.

Methyl (O-methyl-9-((4-(N-(3ß-hydroxy-lup-20(29)-en-28-oyl)-amino)methyl)-1H-1,2,3-triazolyl)-5-acetamido3,5-dideoxy-D-glycero- $\alpha$-D-galacto-2-nonulopyranosyl)onate (30). Prepared from 13 and 27 according to general procedure $\mathrm{A}$, the residue was purified by column chromatography (eluent: $\mathrm{DCM} / \mathrm{MeOH}$ $=12: 1)$ over silica gel to afford compound 30 as a white solid in $79 \%$ yield. $R_{\mathrm{f}}=0.31(\mathrm{DCM} / \mathrm{MeOH}$ $=12: 1) ;{ }^{1} \mathrm{H}-\mathrm{NMR}\left(400 \mathrm{MHz}, \mathrm{CD}_{3} \mathrm{OD}\right): \delta 7.82(\mathrm{~s}, 1 \mathrm{H}), 4.82\left(\mathrm{~m}, 1 \mathrm{H}\right.$, overlap with $\left.\mathrm{H}_{2} \mathrm{O}\right), 4.66(\mathrm{~s}, 1 \mathrm{H})$, $4.54(\mathrm{~s}, 1 \mathrm{H}), 4.37(\mathrm{~s}, 2 \mathrm{H}), 4.32(\mathrm{dd}, 1 \mathrm{H}, J=8.6,14.0 \mathrm{~Hz}), 4.09(\mathrm{~m}, 1 \mathrm{H}), 3.78(\mathrm{~s}, 3 \mathrm{H}), 3.73(\mathrm{t}, 1 \mathrm{H}, J=9.8)$, 3.55-3.63 (m, 2H), 3.38-3.40 (m, 1H), 3.27 (m, 4H), 3.02-2.10 (m, 2H), 2.60 (dd, 1H, J = 4.6, $12.2 \mathrm{~Hz})$, 2.45-2.51 (m, 1H), 2.08-2.11 (m, 1H), $1.96(\mathrm{~s}, 3 \mathrm{H}), 0.93-1.85(\mathrm{~m}$, other aliphatic ring protons), 1.64, 0.95, $0.91\left(\mathrm{~s}, 3 \mathrm{H}\right.$ each, $\left.3 \times \mathrm{CH}_{3}\right), 0.82\left(\mathrm{~s}, 6 \mathrm{H}, 2 \times \mathrm{CH}_{3}\right), 0.72\left(\mathrm{~s}, 3 \mathrm{H}, \mathrm{CH}_{3}\right), 0.66(\mathrm{~d}, 1 \mathrm{H}, J=8.5 \mathrm{~Hz}) ;{ }^{13} \mathrm{C}-\mathrm{NMR}$ (100 MHz, CD $\left.{ }_{3} \mathrm{OD}\right): \delta 179.13,175.19,170.71,152.29,110.01,100.40,79.64,74.67,71.65,71.40,68.40$, 56.94, 56.90, 54.89, 53.82, 53.35, 52.14, 52.09, 51.43, 48.09, 43.49, 42.01, 41.41, 40.11, 39.95, 39.17, 38.97, $38.33,35.58,35.53,33.99,31.94,30.56,28.64,28.04,27.00,22.71,22.15,19.66,19.47,16.82,16.69,16.17$, 15.12; ESI-HRMS calcd. for $\mathrm{C}_{46} \mathrm{H}_{74} \mathrm{O}_{10} \mathrm{~N}_{5}[\mathrm{M}+\mathrm{H}]^{+}:$: 856.5430, found 856.5411 .

Methyl (O-methyl-5-(N-(3ß-hydroxy-olean-12-en-28-oyl)-amino)acetyl-4,7,8,9-tetra-O-acetyl-3,5-dideoxy-Dglycero- $\alpha$-D-galacto-2-nonulopyranosyl)onate (34). Prepared from 10 and 31 according to general procedure $C$, the residue was purified by column chromatography (eluent: $\mathrm{PE} / \mathrm{Act}=1: 1$ ) over silica gel to afford compound 34 as a white solid in $82 \%$ yield. $R_{\mathrm{f}}=0.23$ (PE/ Act $\left.=1: 1\right) ;{ }^{1} \mathrm{H}-\mathrm{NMR}(400 \mathrm{MHz}$, $\left.\mathrm{CDCl}_{3}\right): \delta 6.99(\mathrm{~d}, 1 \mathrm{H}, J=9.4 \mathrm{~Hz}), 6.75(\mathrm{brs}, 1 \mathrm{H}), 5.44-5.48(\mathrm{~m}, 2 \mathrm{H}), 5.33(\mathrm{dd}, 1 \mathrm{H}, J=2.2,9.2 \mathrm{~Hz}), 4.77$ $(\mathrm{m}, 1 \mathrm{H}), 4.25(\mathrm{dd}, 1 \mathrm{H}, J=2.6,12.4 \mathrm{~Hz}), 4.18(\mathrm{dd}, 1 \mathrm{H}, J=2.2,10.7 \mathrm{~Hz}), 4.02-4.11(\mathrm{~m}, 3 \mathrm{H}), 3.80(\mathrm{~s}, 3 \mathrm{H})$, $3.53(\mathrm{dd}, 1 \mathrm{H}, J=3.2,16.2 \mathrm{~Hz}), 3.31(\mathrm{~s}, 3 \mathrm{H}), 3.22(\mathrm{t}, 1 \mathrm{H}, J=5.2 \mathrm{~Hz}), 2.57-2.64(\mathrm{~m}, 2 \mathrm{H}), 2.15,2.13,2.04$, 2.00 (s, 3H each, $\left.4 \times \mathrm{CH}_{3} \mathrm{CO}\right), 0.96-2.02$ (m, other aliphatic ring protons), 1.18, 0.99, 0.93, 0.91, 0.89, 0.79, 0.77 (s, 3H each, $\left.7 \times \mathrm{CH}_{3}\right) ;{ }^{13} \mathrm{C}-\mathrm{NMR}\left(100 \mathrm{MHz}, \mathrm{CDCl}_{3}\right): \delta 179.04,170.75,170.47,170.04,169.93$, $169.71,168.14,144.17,123.62,99.03,79.07,76.84,72.37,69.30,67.93,67.40,62.68,55.24,52.77,52.60$, $49.00,47.72,46.76,46.29,44.01,42.14,42.04,39.48,38.88,38.65,38.15,37.06,34.34,33.09,32.48,32.44$, $30.83,28.22,27.32,25.96,24.20,23.69,23.54,21.24,20.99,20.91,18.41,16.80,15.73,15.53$; ESI-HRMS calcd. for $\mathrm{C}_{51} \mathrm{H}_{78} \mathrm{~N}_{2} \mathrm{NaO}_{15}[\mathrm{M}+\mathrm{Na}]^{+}$: 981.5294, found 981.5294 .

Methyl (O-methyl-5-(N-(3ß-hydroxy-olean-12-en-28-oyl)-amino)acetyl-3,5-dideoxy-D-glycero- $\alpha$-D-galacto-2nonulopyranosyl)onate (35). Prepared from 34 according to general procedure $\mathrm{B}$, the residue was purified by chromatography (eluent: $\mathrm{DCM} / \mathrm{MeOH}=10: 1$ ) over silica gel to afford compound 35 as a white solid in $85 \%$ yield. $R_{\mathrm{f}}=0.24(\mathrm{DCM} / \mathrm{MeOH}=10: 1) ;{ }^{1} \mathrm{H}-\mathrm{NMR}\left(400 \mathrm{MHz}, \mathrm{CD}_{3} \mathrm{OD}\right): \delta 7.53(\mathrm{t}, 1 \mathrm{H}, J=4.8 \mathrm{~Hz})$, $5.38(\mathrm{brs}, 1 \mathrm{H}), 3.59-3.93(\mathrm{~m}, 11 \mathrm{H}), 3.50(\mathrm{dd}, 1 \mathrm{H}, J=1.3,8.7 \mathrm{~Hz}), 3.35(\mathrm{~s}, 3 \mathrm{H}), 3.15(\mathrm{dd}, 1 \mathrm{H}, J=4.8$, $11.0 \mathrm{~Hz}), 2.78(\mathrm{dd}, 1 \mathrm{H}, J=3.4,9.6 \mathrm{~Hz}), 2.66(\mathrm{dd}, 1 \mathrm{H}, J=4.6,12.8 \mathrm{~Hz}), 2.10(\mathrm{dt}, 1 \mathrm{H}, \mathrm{J}=3.3,12.3 \mathrm{~Hz})$, $1.88-2.01(\mathrm{~m}, 2 \mathrm{H}), 0.99-1.83$ (m, other aliphatic ring protons), 1.18, $0.97\left(\mathrm{~s}, 3 \mathrm{H}\right.$ each, $\left.2 \times \mathrm{CH}_{3}\right), 0.95$ (s, $\left.6 \mathrm{H}, 2 \times \mathrm{CH}_{3}\right), 0.92,0.78,0.76\left(\mathrm{~s}, 3 \mathrm{H}\right.$ each, $\left.3 \times \mathrm{CH}_{3}\right), 0.75(\mathrm{~d}, 1 \mathrm{H}, J=11.2 \mathrm{~Hz}) ;{ }^{13} \mathrm{C}-\mathrm{NMR}(100 \mathrm{MHz}$, $\left.\mathrm{CD}_{3} \mathrm{OD}\right): \delta 180.88,173.08,170.85,145.03,124.42,100.32,79.68,74.74,72.61,70.37,68.57,65.16,56.70$, $53.85,53.35,52.00,49.00,47.65,47.55,43.83,42.92,42.75,41.32,40.67,39.84,38.12,35.09,34.00,33.82$, $33.53,31.61,28.75,28.47,27.86,26.45,24.59,24.28,24.04,19.48,17.56,16.33,16.05$; ESI-HRMS calcd. for $\mathrm{C}_{43} \mathrm{H}_{70} \mathrm{~N}_{2} \mathrm{NaO}_{11}[\mathrm{M}+\mathrm{Na}]^{+}:$813.4872, found 813.4876.

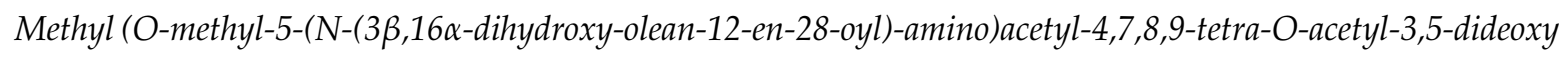
-D-glycero- $\alpha$-D-galacto-2-nonulopyranosyl)onate (36). Prepared from 10 and 32 according to general procedure $C$, the residue was purified by column chromatography (eluent: $\mathrm{PE} / \mathrm{Act}=1: 1$ ) over silica 
gel to afford compound 36 as a white solid in $84 \%$ yield. $R_{\mathrm{f}}=0.20(\mathrm{PE} / \mathrm{Act}=1: 1) ;{ }^{1} \mathrm{H}-\mathrm{NMR}(400 \mathrm{MHz}$, $\mathrm{CDCl}_{3}$ ): $\delta 7.84$ (brs, $\left.1 \mathrm{H}\right), 7.08(\mathrm{~d}, 1 \mathrm{H}, J=5.2 \mathrm{~Hz}), 5.67(\mathrm{brs}, 1 \mathrm{H}), 5.46-5.49(\mathrm{~m}, 1 \mathrm{H}), 5.33(\mathrm{dd}, 1 \mathrm{H}, J=2.3$, $8.7 \mathrm{~Hz}), 4.79(\mathrm{dt}, 1 \mathrm{H}, J=4.2,11.2 \mathrm{~Hz}), 4.30-4.41(\mathrm{~m}, 3 \mathrm{H}), 4.04-4.19(\mathrm{~m}, 3 \mathrm{H}), 3.84(\mathrm{~s}, 3 \mathrm{H}), 3.57(\mathrm{~d}, 1 \mathrm{H}$, $J=16.7 \mathrm{~Hz}), 3.31(\mathrm{~s}, 3 \mathrm{H}), 3.22(\mathrm{brd}, 1 \mathrm{H}, J=6.9 \mathrm{~Hz}), 2.89(\mathrm{brs}, 1 \mathrm{H}), 2.66(\mathrm{brd}, 1 \mathrm{H}, J=13.2 \mathrm{~Hz}), 2.60(\mathrm{dd}$, $1 \mathrm{H}, J=4.4,13.0 \mathrm{~Hz}), 2.32(\mathrm{t}, 1 \mathrm{H}, J=13.2 \mathrm{~Hz}), 2.15,2.14,2.04,2.03\left(\mathrm{~s}, 3 \mathrm{H}\right.$ each, $\left.4 \times \mathrm{CH}_{3} \mathrm{CO}\right), 0.99-2.02$ (m, other aliphatic ring protons), 1.42, 1.00, 0.96, 0.90, 0.87, 0.84, $0.80\left(\mathrm{~s}, 3 \mathrm{H}\right.$ each, $\left.7 \times \mathrm{CH}_{3}\right), 0.76(\mathrm{~d}, 1 \mathrm{H}$, $J=11.5 \mathrm{~Hz}) ;{ }^{13} \mathrm{C}-\mathrm{NMR}\left(100 \mathrm{MHz}, \mathrm{CDCl}_{3}\right): \delta 178.19,170.71,170.53,170.07,170.02,169.65,169.16,143.43$, $124.12,99.27,79.00,76.06,73.03,69.37,68.32,67.54,62.92,55.26,53.03,52.70,48.61,48.53,47.23,46.78$, $44.06,41.80,41.58,39.58,38.87,38.76,38.21,37.02,35.98,34.60,32.67,30.94,30.54,28.21,27.29,26.61$, $24.11,23.74,21.22,21.17,20.93,20.89,18.37,16.80,15.79,15.75$; ESI-HRMS calcd. for $\mathrm{C}_{51} \mathrm{H}_{78} \mathrm{~N}_{2} \mathrm{NaO}_{16}$ $[\mathrm{M}+\mathrm{Na}]^{+}:$997.5244, found 997.5252 .

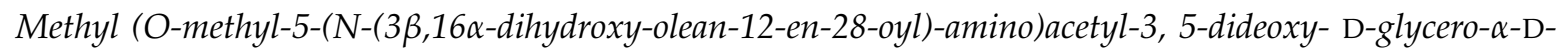
galacto-2-nonulopyranosyl)onate (37). Prepared from 36 according to general procedure $\mathrm{B}$, the residue was purified by chromatography (eluent: $\mathrm{DCM} / \mathrm{MeOH}=10: 1$ ) over silica gel to afford compound 37 as a white solid in $83 \%$ yield. $R_{\mathrm{f}}=0.21(\mathrm{DCM} / \mathrm{MeOH}=10: 1) ;{ }^{1} \mathrm{H}-\mathrm{NMR}\left(400 \mathrm{MHz}, \mathrm{CD}_{3} \mathrm{OD}\right): \delta 7.51(\mathrm{t}$, $1 \mathrm{H}, J=4.7 \mathrm{~Hz}), 5.51(\mathrm{brs}, 1 \mathrm{H}), 4.28(\mathrm{brs}, 1 \mathrm{H}), 3.58-3.95(\mathrm{~m}, 11 \mathrm{H}), 3.46(\mathrm{dd}, 1 \mathrm{H}, J=1.3,8.8 \mathrm{~Hz}), 3.34(\mathrm{~s}$, $3 \mathrm{H}), 3.16(\mathrm{dd}, 1 \mathrm{H}, J=4.9,11.1 \mathrm{~Hz}), 2.89(\mathrm{dd}, 1 \mathrm{H}, J=3.4,13.7 \mathrm{~Hz}), 2.66(\mathrm{dd}, 1 \mathrm{H}, J=4.6,12.8 \mathrm{~Hz}), 2.31$ $(\mathrm{t}, 1 \mathrm{H}, J=13.2 \mathrm{~Hz}), 1.81-1.97(\mathrm{~m}, 4 \mathrm{H}), 1.00-1.75(\mathrm{~m}$, other aliphatic ring protons), $1.38,0.98,0.97,0.96$, 0.90, 0.80, 0.79 (s, 3H each, $\left.7 \times \mathrm{CH}_{3}\right), 0.77(\mathrm{~d}, 1 \mathrm{H}, J=12.6 \mathrm{~Hz}) ;{ }^{13} \mathrm{C}-\mathrm{NMR}\left(100 \mathrm{MHz}, \mathrm{CD}_{3} \mathrm{OD}\right): \delta 180.62$, $172.89,170.82,144.61,124.56,100.30,79.66,75.58,74.73,72.59,70.44,68.57,65.18,56.81,53.80,53.36$, 52.00, 50.29, 48.26, 48.01, 43.92, 42.93, 42.63, 41.28, 40.91, 39.99, 39.84, 38.08, 36.17, 36.06, 33.97, 33.26, $31.12,30.83,28.73,27.90,27.45,25.75,24.55,19.46,17.61,16.33$; ESI-HRMS calcd. for $\mathrm{C}_{43} \mathrm{H}_{70} \mathrm{~N}_{2} \mathrm{NaO}_{12}$ $[\mathrm{M}+\mathrm{Na}]^{+}:$829.4821, found 829.4826 .

Methyl (O-methyl-5-(N-(3ß-hydroxy-urs-12-en-28-oyl)-amino)acetyl-4,7,8,9-tetra-O-acetyl-3,5-dideoxy-Dglycero- $\alpha$-D-galacto-2-nonulopyranosyl)onate (38). Prepared from 10 and 33 according to general procedure $\mathrm{C}$, the residue was purified by column chromatography (eluent: $\mathrm{PE} / \mathrm{Act}=1: 1$ ) over silica gel to afford compound 38 as a white solid in $80 \%$ yield. $R_{\mathrm{f}}=0.24(\mathrm{PE} / \mathrm{Act}=1: 1) ;{ }^{1} \mathrm{H}-\mathrm{NMR}(400 \mathrm{MHz}$, $\left.\mathrm{CDCl}_{3}\right): \delta 6.84(\mathrm{~d}, 1 \mathrm{H}, J=9.0 \mathrm{~Hz}), 6.71(\mathrm{brs}, 1 \mathrm{H}) .5 .44-5.48(\mathrm{~m}, 1 \mathrm{H}), 5.40(\mathrm{brs}, 1 \mathrm{H}), 5.32(\mathrm{dd}, 1 \mathrm{H}, J=1.6$, $9.3 \mathrm{~Hz}), 4.75(\mathrm{~m}, 1 \mathrm{H}), 4.24(\mathrm{dd}, 1 \mathrm{H}, J=2.5,12.4 \mathrm{~Hz}), 4.06-4.17(\mathrm{~m}, 3 \mathrm{H}), 3.98(\mathrm{dd}, 1 \mathrm{H}, J=6.1,16.3 \mathrm{~Hz})$, $3.81(\mathrm{~s}, 3 \mathrm{H}), 3.56(\mathrm{dd}, 1 \mathrm{H}, J=3.2,16.3 \mathrm{~Hz}), 3.31(\mathrm{~s}, 3 \mathrm{H}), 3.18-3.23(\mathrm{~m}, 1 \mathrm{H}), 2.63(\mathrm{dd}, 1 \mathrm{H}, J=4.5,12.7 \mathrm{~Hz})$, 2.15, 2.13, 2.03, 1.99 (s, 3H each, $4 \times \mathrm{CH}_{3} \mathrm{CO}$ ), 1.03-2.06 (m, other aliphatic ring protons), 1.11, 0.99, 0.96, $0.94\left(\mathrm{~s}, 3 \mathrm{H}\right.$ each, $\left.4 \times \mathrm{CH}_{3}\right), 0.88\left(\mathrm{~d}, 3 \mathrm{H}, J=6.4 \mathrm{~Hz}, \mathrm{CH}_{3}\right), 0.79,0.76\left(\mathrm{~s}, 3 \mathrm{H}\right.$ each, $\left.2 \times \mathrm{CH}_{3}\right), 0.73(\mathrm{~d}, 1 \mathrm{H}$, $J=11.5 \mathrm{~Hz}) ;{ }^{13} \mathrm{C}-\mathrm{NMR}\left(100 \mathrm{MHz}, \mathrm{CDCl}_{3}\right): \delta 178.80,170.73,170.49,170.03,169.97,169.85,168.12,138.99$, $126.50,99.01,79.11,72.37,69.30,67.95,67.32,62.63,55.26,53.62,52.79,52.60,48.93,47.73$ (2C), 43.87, $42.44,39.84,39.66,39.13,38.87,38.79,38.17,37.19,37.05,32.87,31.06,28.24,27.86,27.31,25.18,23.53$, $21.34,21.23,21.03,21.00,20.90,18.40,17.28,16.78,15.77,15.60$; ESI-HRMS calcd. for $\mathrm{C}_{51} \mathrm{H}_{79} \mathrm{~N}_{2} \mathrm{O}_{15}$ $[\mathrm{M}+\mathrm{H}]^{+}:$959.5475, found 959.5472 .

Methyl (O-methyl-5-(N-(3ß-hydroxy-urs-12-en-28-oyl)-amino)acetyl-3,5-dideoxy-D-glycero- $\alpha$-D-galacto-2nonulopyranosyl)onate (39). Prepared from 38 according to general procedure $\mathrm{B}$, the residue was purified by chromatography (eluent: $\mathrm{DCM} / \mathrm{MeOH}=10: 1$ ) over silica gel to afford compound 37 as a white solid in $86 \%$ yield. $R_{\mathrm{f}}=0.25(\mathrm{DCM} / \mathrm{MeOH}=10: 1) ;{ }^{1} \mathrm{H}-\mathrm{NMR}\left(400 \mathrm{MHz}, \mathrm{CD}_{3} \mathrm{OD}\right): \delta 5.37$ (brs, $1 \mathrm{H}), 3.85-3.91(\mathrm{~m}, 6 \mathrm{H}), 3.59-3.80(\mathrm{~m}, 5 \mathrm{H}), 3.49(\mathrm{~d}, 1 \mathrm{H}, J=8.8 \mathrm{~Hz}), 3.34(\mathrm{~s}, 3 \mathrm{H}), 3.16(\mathrm{dd}, 1 \mathrm{H}, J=4.8,11.0$ $\mathrm{Hz}), 2.66(\mathrm{dd}, 1 \mathrm{H}, J=4.7,12.8 \mathrm{~Hz}), 2.12(\mathrm{~d}, 1 \mathrm{H}, J=11.0 \mathrm{~Hz}), 2.08(\mathrm{dd}, 2 \mathrm{H}, J=4.1,13.5 \mathrm{~Hz}), 1.95-1.98$ $(\mathrm{m}, 2 \mathrm{H}), 0.98-1.76\left(\mathrm{~m}\right.$, other aliphatic ring protons), $1.13\left(\mathrm{~s}, 3 \mathrm{H}, \mathrm{CH}_{3}\right), 0.98\left(\mathrm{~s}, 6 \mathrm{H}, 2 \times \mathrm{CH}_{3}\right), 0.97$ (s, $\left.3 \mathrm{H}, \mathrm{CH}_{3}\right), 0.92\left(\mathrm{~d}, 3 \mathrm{H}, J=6.4 \mathrm{~Hz}, \mathrm{CH}_{3}\right), 0.78\left(2 \times \mathrm{s}, 6 \mathrm{H}, 2 \times \mathrm{CH}_{3}\right), 0.75(\mathrm{~d}, 1 \mathrm{H}, J=10.7 \mathrm{~Hz}) ;{ }^{13} \mathrm{C}-\mathrm{NMR}$ (100 MHz, CD $\left.{ }_{3} \mathrm{OD}\right): \delta 180.66,173.00,170.83,139.65,127.62,100.31,79.65,74.71,72.62,70.37,68.54$, $65.14,56.67,54.28,53.84,53.35,52.00,49.00,48.90,43.77,43.29,41.31,40.85,40.81,40.30,39.99,39.82$, $38.38,38.06,34.12,31.89,28.93,28.78,27.88,25.45,24.43,24.08,21.6,19.45,17.75,17.58,16.39,16.21$; ESI-HRMS calcd. for $\mathrm{C}_{43} \mathrm{H}_{70} \mathrm{~N}_{2} \mathrm{NaO}_{11}[\mathrm{M}+\mathrm{Na}]^{+}$: 813.4872, found 813.4879. 


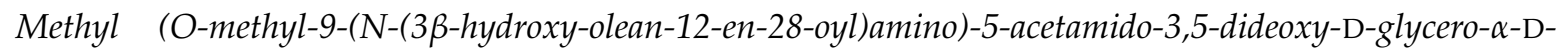
galacto-2-nonulopyranosyl)onate (40). Prepared from 14 and 31 according to general procedure $C$, the residue was purified by column chromatography (eluent: $\mathrm{DCM} / \mathrm{MeOH}=12: 1$ ) over silica gel to afford compound 40 as a white solid in $80 \%$ yield. $R_{\mathrm{f}}=0.27(\mathrm{DCM} / \mathrm{MeOH}=12: 1) ;{ }^{1} \mathrm{H}-\mathrm{NMR}(400 \mathrm{MHz}$, $\left.\mathrm{CD}_{3} \mathrm{OD}\right): \delta 7.15(\mathrm{t}, 1 \mathrm{H}, J=5.0 \mathrm{~Hz}), 5.39$ (brs, $\left.1 \mathrm{H}\right), 3.88(\mathrm{dt}, 1 \mathrm{H}, J=3.2,8.1 \mathrm{~Hz}), 3.84(\mathrm{~s}, 3 \mathrm{H}), 3.73-3.78(\mathrm{~m}$, $2 \mathrm{H}), 3.60-3.67(\mathrm{~m}, 2 \mathrm{H}), 3.36(\mathrm{~s}, 1 \mathrm{H}), 3.34(\mathrm{~s}, 3 \mathrm{H}), 3.06-3.17(\mathrm{~m}, 2 \mathrm{H}), 2.74(\mathrm{~d}, 1 \mathrm{H}, J=9.7 \mathrm{~Hz}), 2.63(\mathrm{dd}, 1 \mathrm{H}$, $J=4.4,12.8 \mathrm{~Hz}), 0.98-2.09$ (m, other aliphatic ring protons), 1.99 (s, 3H, $\left.\mathrm{CH}_{3} \mathrm{CO}\right), 1.19,0.97,0.95,0.94$, 0.92, 0.82, $0.78\left(\mathrm{~s}, 3 \mathrm{H}\right.$ each, $\left.7 \times \mathrm{CH}_{3}\right), 0.76(\mathrm{~m}, 1 \mathrm{H}) ;{ }^{13} \mathrm{C}-\mathrm{NMR}\left(100 \mathrm{MHz}, \mathrm{CD}_{3} \mathrm{OD}\right): \delta$ 180.91, 175.00, $170.78,145.1,124.54,100.37,79.65,74.67,72.4,70.65,68.53,56.66,53.81,53.28,52.09,47.73,47.67,44.66$, $43.00,42.96,41.35,40.71,39.83,38.11,35.14,34.00,33.76,33.53,31.62,28.75,28.49,27.86,26.45,24.62$, 24.37, 24.09, 22.76, 19.47, 17.86, 16.31, 15.99; ESI-HRMS calcd. for $\mathrm{C}_{43} \mathrm{H}_{71} \mathrm{~N}_{2} \mathrm{O}_{10}[\mathrm{M}+\mathrm{H}]^{+}:$775.5103, found 775.5089 .

Methyl (O-methyl-9-(N-(3 $\beta, 16 \alpha$-dihydroxy-olean-12-en-28-oyl)amino)-5-acetamido-3,5-dideoxy-D-glycero- $\alpha$-Dgalacto-2-nonulopyranosyl)onate (41). Prepared from 14 and 32 according to general procedure $C$, the residue was purified by column chromatography (eluent: $\mathrm{DCM} / \mathrm{MeOH}=12: 1$ ) over silica gel to afford compound 41 as a white solid in $75 \%$ yield. $R_{\mathrm{f}}=0.24(\mathrm{DCM} / \mathrm{MeOH}=12: 1) ;{ }^{1} \mathrm{H}-\mathrm{NMR}(400 \mathrm{MHz}$, $\left.\mathrm{CD}_{3} \mathrm{OD}\right): \delta 7.17$ (brs, 1H), 5.51 (brs, 1H), 4.33 (brs, 1H), $3.85(\mathrm{~m}, 1 \mathrm{H}), 3.84(\mathrm{~s}, 3 \mathrm{H}), 3.73-3.78$ (m, 2H), 3.58-3.67 (m, 2H), $3.36(\mathrm{~s}, 1 \mathrm{H}), 3.33(\mathrm{~s}, 3 \mathrm{H}), 3.16(\mathrm{dd}, 1 \mathrm{H}, J=4.8,11.0 \mathrm{~Hz}), 3.00-3.06(\mathrm{~m}, 1 \mathrm{H}), 2.81(\mathrm{dd}$, $1 \mathrm{H}, J=2.7,10.6 \mathrm{~Hz}), 2.64(\mathrm{dd}, 1 \mathrm{H}, J=4.5,12.8 \mathrm{~Hz}), 2.37(\mathrm{t}, 1 \mathrm{H}, J=13.2 \mathrm{~Hz}), 1.02-2.01(\mathrm{~m}$, other aliphatic ring protons), $2.00\left(\mathrm{~s}, 3 \mathrm{H}, \mathrm{CH}_{3} \mathrm{CO}\right), 1.39,0.98\left(\mathrm{~s}, 3 \mathrm{H}\right.$ each, $\left.2 \times \mathrm{CH}_{3}\right), 0.96\left(2 \times \mathrm{s}, 6 \mathrm{H}, 2 \times \mathrm{CH}_{3}\right), 0.89,0.83$, $0.78\left(\mathrm{~s}, 3 \mathrm{H}\right.$ each, $\left.3 \times \mathrm{CH}_{3}\right), 0.77(\mathrm{~m}, 1 \mathrm{H}) ;{ }^{13} \mathrm{C}-\mathrm{NMR}\left(100 \mathrm{MHz}, \mathrm{CD}_{3} \mathrm{OD}\right): \delta 180.70,175.08,170.81,144.95$, $124.61,100.35,79.64,75.76,74.72,72.36,70.65,68.52,56.77,53.81,53.33,52.07,50.28,48.21,48.16,44.51$, $42.90,42.88,41.35,40.87,39.99,39.84,38.09,36.39,36.04,33.92,33.23,31.59,31.22,28.72,27.90,27.30$, 25.44, 24.58, 22.77, 19.44, 17.87, 16.32, 16.22; ESI-HRMS calcd. for $\mathrm{C}_{43} \mathrm{H}_{71} \mathrm{~N}_{2} \mathrm{O}_{11}[\mathrm{M}+\mathrm{H}]^{+}$: 791.5052, found 791.5032 .

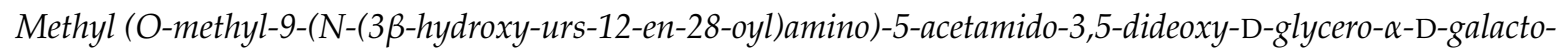
2-nonulopyranosyl)onate (42). Prepared from 14 and 33 according to general procedure $C$, the residue was purified by column chromatography (eluent: $\mathrm{DCM} / \mathrm{MeOH}=12: 1$ ) over silica gel to afford compound 42 as a white solid in $83 \%$ yield. $R_{\mathrm{f}}=0.28(\mathrm{DCM} / \mathrm{MeOH}=12: 1) ;{ }^{1} \mathrm{H}-\mathrm{NMR}\left(400 \mathrm{MHz}, \mathrm{CDCl}_{3}\right): \delta 7.24$ (brs, 1H), 6.61 (brs, 1H), $5.34(\mathrm{~s}, 1 \mathrm{H}), 4.99$ (s, 1H), 4.54 (brs, 1H), 3.95 (s, 1H), 3.85 (s, 4H), 3.71 (s, 3H), $3.51(\mathrm{~d}, 1 \mathrm{H}, J=7.9 \mathrm{~Hz}), 3.32(\mathrm{~s}, 4 \mathrm{H}), 3.20(\mathrm{~m}, 1 \mathrm{H}), 3.14(\mathrm{brs}, 1 \mathrm{H}), 2.71(\mathrm{~d}, 1 \mathrm{H}, J=12.2 \mathrm{~Hz}), 2.03(\mathrm{~s}, 3 \mathrm{H}$, $\mathrm{CH}_{3} \mathrm{CO}$ ), 1.04-1.99 (m, other aliphatic ring protons), 1.10, 0.99, 0.95, 0.89, 0.87, 0.79, 0.77 (s, 3H each, $\left.7 \times \mathrm{CH}_{3}\right), 0.72(\mathrm{~d}, 1 \mathrm{H}, \mathrm{J}=11.2 \mathrm{~Hz}) ;{ }^{13} \mathrm{C}-\mathrm{NMR}\left(100 \mathrm{MHz}, \mathrm{CDCl}_{3}\right): \delta 179.46,173.63,169.66,138.91,126.19$, 99.05, 78.91, 73.48, 70.91, 70.36, 67.41, 55.10, 53.60, 53.48, 53.38, 53.12, 51.55, 47.79, 47.54, 43.5, 42.39, $39.73,39.55,38.97,38.73,38.64,37.29,36.90,32.79,30.87,28.13,27.78,27.18,24.91,23.37,23.27,23.04$, $21.18,18.26,17.15,16.87,15.64,15.44$; ESI-HRMS calcd. for $\mathrm{C}_{43} \mathrm{H}_{71} \mathrm{~N}_{2} \mathrm{O}_{10}[\mathrm{M}+\mathrm{H}]^{+}:$775.5103, found 775.5090 .

Methyl (O-methyl-5-(N-(3ß-hydroxy-lup-20(29)-en-28-oyl)-amino)acetyl-4,7,8,9-tetra-O-acetyl-3,5-dideoxy-Dglycero- $\alpha$-D-galacto- 2-nonulopyranosyl)onate (44). Prepared from 10 and 43 according to general procedure $C$, the residue was purified by column chromatography (eluent: $\mathrm{PE} / \mathrm{Act}=1: 1$ ) over silica gel to afford compound 44 as a white solid in $75 \%$ yield. $R_{\mathrm{f}}=0.25$ (PE/ Act $\left.=1: 1\right) ;{ }^{1} \mathrm{H}-\mathrm{NMR}(400 \mathrm{MHz}$, $\left.\mathrm{CDCl}_{3}\right): \delta 6.41(\mathrm{t}, 1 \mathrm{H}, J=5.3 \mathrm{~Hz}), 6.24(\mathrm{~d}, 1 \mathrm{H}, J=9.5 \mathrm{~Hz}), 5.43-5.47(\mathrm{~m}, 1 \mathrm{H}), 5.29(\mathrm{t}, 1 \mathrm{H}, J=7.3 \mathrm{~Hz})$, $4.78-4.85$ (m, 1H), 4.76 (brs 1H), 4.61 (brs, 1H), 4.23 (dd, 1H, J = 2.6, $12.4 \mathrm{~Hz}), 4.05-4.10(\mathrm{~m}, 3 \mathrm{H}), 3.91$ $(\mathrm{dd}, 1 \mathrm{H}, J=5.3,15.6 \mathrm{~Hz}), 3.83(\mathrm{~s}, 3 \mathrm{H}), 3.66(\mathrm{dd}, 1 \mathrm{H}, J=5.5,15.6 \mathrm{~Hz}), 3.31(\mathrm{~s}, 3 \mathrm{H}), 3.12-3.19(\mathrm{~m}, 2 \mathrm{H}), 2.63$ $(\mathrm{dd}, 1 \mathrm{H}, J=4.6,12.7 \mathrm{~Hz}), 2.38(\mathrm{dt}, 1 \mathrm{H}, J=3.0,11.6 \mathrm{~Hz}), 2.13\left(\mathrm{~s}, 6 \mathrm{H}, 2 \times \mathrm{CH}_{3} \mathrm{CO}\right), 2.03,2.02(\mathrm{~s}, 3 \mathrm{H}$ each, $\left.2 \times \mathrm{CH}_{3} \mathrm{CO}\right), 0.87-2.06$ (m, other aliphatic ring protons), 1.70, 0.97, 0.96, 0.90, 0.81, 0.75 (s, 3H each, $\left.6 \times \mathrm{CH}_{3}\right), 0.68(\mathrm{~d}, 1 \mathrm{H}, J=8.8 \mathrm{~Hz}) ;{ }^{13} \mathrm{C}-\mathrm{NMR}\left(100 \mathrm{MHz}, \mathrm{CDCl}_{3}\right): \delta 177.50,170.74,170.68,170.46,170.38$, $170.05,168.05,150.81,109.65,98.99,79.07,72.25,69.30,67.79,67.39,62.48,55.98,55.47,52.89,52.61$, $50.69,50.26,49.06,46.73,43.85,42.58,40.84,38.97,38.83,38.27,38.08,37.90,37.31,34.45,33.81,31.27$, 
29.59, 28.12, 27.50, 25.70, 21.21, 21.06, 20.97, 20.91, 19.58, 18.42, 16.24, 16.22, 15.52, 14.77; ESI-HRMS calcd. for $\mathrm{C}_{51} \mathrm{H}_{79} \mathrm{~N}_{2} \mathrm{O}_{15}[\mathrm{M}+\mathrm{H}]^{+}$: 959.5475, found 959.5481 .

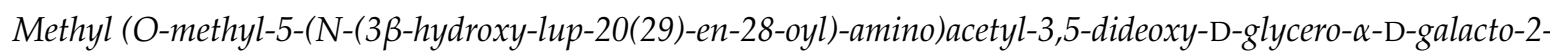
nonulopyranosyl)onate (45). Prepared from 44 according to general procedure $\mathrm{B}$, the residue was purified by chromatography (eluent: $\mathrm{DCM} / \mathrm{MeOH}=10: 1$ ) over silica gel to afford compound 45 as a white solid in $78 \%$ yield. $R_{\mathrm{f}}=0.25(\mathrm{DCM} / \mathrm{MeOH}=10: 1) ;{ }^{1} \mathrm{H}-\mathrm{NMR}\left(400 \mathrm{MHz}, \mathrm{CD}_{3} \mathrm{OD}\right): \delta 7.86(\mathrm{t}, 1 \mathrm{H}, J=5.6 \mathrm{~Hz})$, $4.73(\mathrm{~s}, 1 \mathrm{H}), 4.59(\mathrm{~s}, 1 \mathrm{H}), 3.61-3.88(\mathrm{~m}, 10 \mathrm{H}), 3.58-3.59(\mathrm{~m}, 1 \mathrm{H}), 3.56(\mathrm{~s}, 1 \mathrm{H}), 3.35(\mathrm{~s}, 3 \mathrm{H}), 3.05-3.15$ $(\mathrm{m}, 2 \mathrm{H}), 2.68(\mathrm{dd}, 1 \mathrm{H}, J=4.6,12.8 \mathrm{~Hz}), 2.49(\mathrm{dt}, 1 \mathrm{H}, J=3.2,12.7 \mathrm{~Hz}), 2.16-2.18(\mathrm{~m}, 1 \mathrm{H}$, overlap with acetone), 1.86-1.98 (m, 2H), 0.91-1.78 (m, other aliphatic ring protons), 1.70, $1.00\left(\mathrm{~s}, 3 \mathrm{H}\right.$ each, $\left.2 \times \mathrm{CH}_{3}\right)$, $0.95\left(\mathrm{~s}, 6 \mathrm{H}, 2 \times \mathrm{CH}_{3}\right), 0.86,0.75\left(\mathrm{~s}, 3 \mathrm{H}\right.$ each, $\left.2 \times \mathrm{CH}_{3}\right), 0.71(\mathrm{~d}, 1 \mathrm{H}, J=8.6 \mathrm{~Hz}) ;{ }^{13} \mathrm{C}-\mathrm{NMR}(100 \mathrm{MHz}$, $\left.\mathrm{CD}_{3} \mathrm{OD}\right): \delta 179.96,174.01,170.89,152.30,110.01,100.29,79.65,74.94,72.73,70.40,68.52,65.38,57.05$, $56.89,53.85,53.40,52.08,51.99,51.38,48.06,43.65,43.54,42.00,41.37,40.11,39.94,39.28,38.99,38.33$, $35.61,34.06,32.03,30.66,28.64,28.04,27.01,22.15,19.82,19.47,16.82,16.80,16.13,15.11$; ESI-HRMS calcd. for $\mathrm{C}_{43} \mathrm{H}_{70} \mathrm{~N}_{2} \mathrm{NaO}_{11}[\mathrm{M}+\mathrm{Na}]^{+}:$: 813.4872, found 813.4878.

Methyl (O-methyl-9-(N-(3ß-hydroxy-lup-20(29)-en-28-oyl)amino)-5-acetamido-3,5-dideoxy-D-glycero- $\alpha$-Dgalacto-2-nonulopyranosyl)onate (46). Prepared from 14 and 43 according to general procedure $\mathrm{C}$, the residue was purified by column chromatography (eluent: $\mathrm{DCM} / \mathrm{MeOH}=12: 1$ ) over silica gel to afford compound 46 as a white solid in 77\% yield. $R_{\mathrm{f}}=0.29(\mathrm{DCM} / \mathrm{MeOH}=12: 1) ;{ }^{1} \mathrm{H}-\mathrm{NMR}(400 \mathrm{MHz}$, $\left.\mathrm{CD}_{3} \mathrm{OD}\right): \delta 7.37(\mathrm{t}, 1 \mathrm{H}, J=5.4 \mathrm{~Hz}), 4.72(\mathrm{~s}, 1 \mathrm{H}), 4.59(\mathrm{~s}, 1 \mathrm{H}), 3.90-3.95(\mathrm{~m}, 1 \mathrm{H}), 3.84(\mathrm{~s}, 3 \mathrm{H}), 3.78(\mathrm{t}$, $1 \mathrm{H}, J=10.2 \mathrm{~Hz}), 3.61-3.67(\mathrm{~m}, 2 \mathrm{H}), 3.56(\mathrm{dt}, 1 \mathrm{H}, J=4.3,13.9 \mathrm{~Hz}), 3.41(\mathrm{t}, 1 \mathrm{H}, J=5.9 \mathrm{~Hz}), 3.33-3.37$ $(\mathrm{m}, 4 \mathrm{H}), 3.06-3.14(\mathrm{~m}, 2 \mathrm{H}), 2.64(\mathrm{dd}, 1 \mathrm{H}, J=4.5,12.7 \mathrm{~Hz}), 2.54(\mathrm{dt}, 1 \mathrm{H}, J=2.6,11.1 \mathrm{~Hz}), 2.10-2.15(\mathrm{~m}$, $1 \mathrm{H}), 1.98\left(\mathrm{~s}, 3 \mathrm{H}, \mathrm{CH}_{3} \mathrm{CO}\right), 1.69,1.00\left(\mathrm{~s}, 3 \mathrm{H}\right.$ each, $\left.2 \times \mathrm{CH}_{3}\right), 0.94-1.92(\mathrm{~m}$, other aliphatic ring protons), $0.95\left(\mathrm{~s}, 6 \mathrm{H}, 2 \times \mathrm{CH}_{3}\right), 0.85,0.75\left(\mathrm{~s}, 3 \mathrm{H}\right.$ each, $\left.2 \times \mathrm{CH}_{3}\right), 0.70(\mathrm{~d}, 1 \mathrm{H}, J=9.8 \mathrm{~Hz}) ;{ }^{13} \mathrm{C}-\mathrm{NMR}(100 \mathrm{MHz}$, $\left.\mathrm{CD}_{3} \mathrm{OD}\right): \delta 179.67,174.82,170.82,152.24,110.12,100.31,79.64,74.56,71.88,70.99,68.63,57.15,56.89$, 53.84, 53.30, 52.08, 52.04, 51.42, 48.16, 43.84, 43.54, 41.99, 41.39, 40.11, 39.94, 39.43, 38.99, 38.33, 35.60, $34.29,32.05,30.60,28.64,28.04,26.96,22.89,22.13,19.66,19.45,16.90,16.78,16.13,15.14$; ESI-HRMS calcd. for $\mathrm{C}_{43} \mathrm{H}_{71} \mathrm{~N}_{2} \mathrm{O}_{10}[\mathrm{M}+\mathrm{H}]^{+}:$:775.5103, found 775.5089.

\subsection{Bioassays}

\subsubsection{Cytotoxicity Assay}

The assay was performed as previously described with some modifications [39]. Cells were seeded in 96-well plates in DMEM supplemented with $10 \%$ FBS and cultured overnight at $37^{\circ} \mathrm{C}$ in $5 \% \mathrm{CO}_{2}$. Then, the test compounds were added and the cells were further incubated at $37^{\circ} \mathrm{C}$ in $5 \%$ $\mathrm{CO}_{2}$ for $40 \mathrm{~h}$. Cell viability was assessed using the CellTiter-Glo assay kit (as recommended by the supplier, Promega Corp., Madison, WI, USA) and the plates were read using a plate reader (Tecan Infinite M2000 PRO; Tecan Group Ltd., Mannedorf, Switzerland). Viability was calculated using the background-corrected absorbance as follows:

$$
\text { Viability }(\%)=\text { A of experiment well } / \text { A of control well } \times 100 \%
$$

\subsubsection{MTT Assay}

The compounds were dissolved in DMSO and diluted to the required concentration with the culture medium when used. The cells harvested from the exponential phase were equivalently seeded into a 96-well plate and compounds were then added to the wells to achieve final concentrations ranging from $10^{-7}$ to $10^{-5} \mathrm{M}$. Control wells were prepared by the addition of the culture medium. Wells containing the culture medium without cells were used as blanks. The plates were incubated at $37^{\circ} \mathrm{C}$ in a $5 \% \mathrm{CO}_{2}$ incubator for $44 \mathrm{~h}$. The MTT assay was performed (as described by Mosmann [35]). Upon completion of the incubation, a stock MTT dye solution $(20 \mu \mathrm{L}, 5 \mathrm{mg} / \mathrm{mL})$ was added to each 
well. After $4 \mathrm{~h}$ of incubation, 2-propanol $(100 \mu \mathrm{L})$ was added to solubilize the MTT formazan. The OD of each well was then determined on a microplate spectrophotometer, at a wavelength of $570 \mathrm{~nm}$.

\subsubsection{CPE Reduction Assay}

MDCK cells were seeded into 96-well plates in DMEM, supplemented with 10\% FBS and incubated overnight at $37^{\circ} \mathrm{C}$ under $5 \% \mathrm{CO}_{2}$. The culture medium was replaced by the test compound and the influenza virus (MOI = 0.1)-DMEM, supplemented with $1 \% \mathrm{FBS}$ and $2 \mu \mathrm{g} / \mathrm{mL}$ TPCK-treated trypsin. The final concentration of DMSO was 1\%. After $40 \mathrm{~h}$ of incubation, CellTiter-Glo reagent (Promega Corp., Madison, WI, USA) was added and the CellTiter-Glo assay was performed.

\section{Conclusions}

We synthesized and characterized a series of novel sialic acid (C-5 or C-9)-pentacyclic triterpene conjugates, and their cytotoxicity and anti-influenza A/WSN/33 virus activity were evaluated. Two sialic acid (C-9)-ursolic acid conjugates $\mathbf{2 6}$ and $\mathbf{4 2}$ showed strong cytotoxicity to MDCK cells at a concentration of $100 \mu \mathrm{M}$. Most compounds had no significant activity against the influenza A/WSN/33 strain, except that four compounds 20, 28, 36, and 44 showed weak anti-influenza virus activity. Compound 20 exhibited a synergistic effect (when combined OSV) in inhibiting influenza infection. These results indicated that the positions of C-5 and C-9 of sialic acid were important for its binding with the HA protein during virus entry into host cells, while C-4 and C-2 hydroxy were not critical for the binding process and could be replaced with hydrophobic moieties. Therefore, the synergistic effect of pentacyclic triterpene with other anti-influenza virus inhibitors may provide a new option for the treatment of the influenza virus infection.

Supplementary Materials: Supplementary materials are available online. Table S1: The cytotoxicity of compounds 26 and 42 against HL-60, Hela and A549 cell lines. Selected ${ }^{1} \mathrm{H}-,{ }^{13} \mathrm{C}-\mathrm{NMR}$, and HRMS spectra.

Acknowledgments: This work was supported by the National Natural Science Foundation of China (Grants Nos. $81573269,81373271,21572015$ and 81361168002).

Author Contributions: D.-M.Z conceived and designed the experiments; X.H., Y.-Y.S., Z.-B.F. and P.-X.J. synthesized the conjugates; L.-L.S. and J.-Q.S. carried out the in vitro anti-influenza experiments; F.-X.R. and M.L. performed the in vitro antitumor experiments; S.-X.W. and Z.-Y.T. analyzed the NMR data; Y.-M.Z. and S.-L.X. wrote the paper.

Conflicts of Interest: The authors declare no conflict of interest.

\section{References}

1. Zambon, M.C. Epidemiology and pathogenesis of influenza. J. Antimicrob. Chemother. 1999, 44, 3-9. [CrossRef] [PubMed]

2. Poland, G.A.; Jacobson, R.M.; Targonski, P.V. Avian and pandemic influenza: An overview. Vaccine 2007, 25, 3057-3061. [CrossRef] [PubMed]

3. Wu, Y.; Wu, Y.; Tefsen, B.; Shi, Y.; Gao, G.F. Bat-derived influenza-like viruses H17N10 and H18N11. Trends Microbiol. 2014, 22, 183-191. [CrossRef] [PubMed]

4. Carrat, F.; Flahault, A. Influenza vaccine: The challenge of antigenic drift. Vaccine 2007, 25, 6852-6862. [CrossRef] [PubMed]

5. Bouvier, N.M.; Palese, P. The biology of influenza viruses. Vaccine 2008, 26, D49-D53. [CrossRef] [PubMed]

6. Hurt, A.C.; Ho, H.T.; Barr, I. Resistance to anti-influenza drugs: Adamantanes and neuraminidase inhibitors. Expert Rev. Anti-infect. Ther. 2006, 4, 795-805. [CrossRef] [PubMed]

7. Bright, R.A.; Medina, M.J.; Xu, X.Y.; Perez-Oronoz, G.; Wallis, T.R.; Davis, X.H.M.; Povinelli, L.; Cox, N.J.; Klimov, A.I. Incidence of adamantane resistance among influenza a (H3N2) viruses isolated worldwide from 1994 to 2005: A cause for concern. Lancet 2005, 366, 1175-1181. [CrossRef]

8. van der Vries, E.; Stelma, F.F.; Boucher, C.A.B. Emergence of a multidrug-resistant pandemic influenza a (H1N1) virus. N. Engl. J. Med. 2010, 363, 1381-1382. [CrossRef] [PubMed] 
9. Hurt, A.C. The epidemiology and spread of drug resistant human influenza viruses. Curr. Opin. Virol. 2014, 8, 22-29. [CrossRef] [PubMed]

10. Skehel, J.J.; Wiley, D.C. Receptor binding and membrane fusion in virus entry: The influenza hemagglutinin. Annu. Rev. Biochem. 2000, 69, 531-569. [CrossRef] [PubMed]

11. Weis, W.; Brown, J.H.; Cusack, S.; Paulson, J.C.; Skehel, J.J.; Wiley, D.C. Structure of the influenza virus haemagglutinin complexed with its receptor, sialic acid. Nature 1988, 333, 426-431. [CrossRef] [PubMed]

12. Varki, A.; Gagneux, P. Multifarious roles of sialic acids in immunity. Ann. N. Y. Acad. Sci. 2012, 1253, $16-36$. [CrossRef] [PubMed]

13. Varki, A. Sialic acids and the host-pathogen interface-roles in hominid evolution. Am. J. Phys. Anthropol. 2010, 233.

14. Klefel, M.J.; von Itzstein, M. Recent advances in the synthesis of sialic acid derivatives and sialylmimetics as biological probes. Chem. Rev. 2002, 102, 471-490.

15. Matrosovich, M.; Klenk, H.D. Natural and synthetic sialic acid-containing inhibitors of influenza virus receptor binding. Rev. Med. Virol. 2003, 13, 85-97. [CrossRef] [PubMed]

16. Laborda, P.; Wang, S.Y.; Voglmeir, J. Influenza neuraminidase inhibitors: Synthetic approaches, derivatives and biological activity. Molecules 2016, 21, 1513. [CrossRef] [PubMed]

17. Vonitzstein, M.; Wu, W.Y.; Kok, G.B.; Pegg, M.S.; Dyason, J.C.; Jin, B.; Phan, T.V.; Smythe, M.L.; White, H.F.; Oliver, S.W.; et al. Rational design of potent sialidase-based inhibitors of influenza-virus replication. Nature 1993, 363, 418-423. [CrossRef] [PubMed]

18. Sato, S.; Fujita, S.; Furuhata, K.; Ogura, H.; Yoshimura, S.; Itoh, M.; Shitori, Y. Synthesis of 2-(5-cholesten-3- $\beta$-yloxy) glycosides of $N$-acetyl-D-neuraminic acid-derivatives. Chem. Pharm. Bull. 1987, 35, 4043-4048. [CrossRef]

19. Koketsu, M.; Nitoda, T.; Sugino, H.; Juneja, L.R.; Kim, M.; Yamamoto, T.; Abe, N.; Kajimoto, T.; Wong, C.H. Synthesis of a novel sialic acid derivative (sialylphospholipid) as an antirotaviral agent. J. Med. Chem. 1997, 40, 3332-3335. [CrossRef] [PubMed]

20. Takahashi, T.; Tsukamoto, H.; Yamada, H. Design and synthesis of a water-soluble taxol analogue: Taxol-sialyl conjugate. Bioorg. Med. Chem. Lett. 1998, 8, 113-116. [CrossRef]

21. Ikeuchi, Y.; Sumiya, M.; Kawamoto, T.; Akimoto, N.; Mikata, Y.; Kishigami, M.; Yano, S.; Sasaki, T.; Yoneda, F. Synthesis and antitumor activities of novel 5-deazaflavin-sialic acid conjugate molecules. Bioorg. Med. Chem. 2000, 8, 2027-2035. [CrossRef]

22. Yu, H.; Yu, H.; Karpel, R.; Chen, X. Chemoenzymatic synthesis of cmp-sialic acid derivatives by a one-pot two-enzyme system: Comparison of substrate flexibility of three microbial $\mathrm{cmp}$-sialic acid synthetases. Bioorg. Med. Chem. 2004, 12, 6427-6435. [CrossRef] [PubMed]

23. Aoki, Y.; Tanimoto, S.; Takahashi, D.; Toshima, K. Photodegradation and inhibition of drug-resistant influenza virus neuraminidase using anthraquinone-sialic acid hybrids. Chem. Commun. 2013, 49, 1169-1171. [CrossRef] [PubMed]

24. Liby, K.T.; Yore, M.M.; Sporn, M.B. Triterpenoids and rexinoids as multifunctional agents for the prevention and treatment of cancer. Nat. Rev. Cancer 2007, 7, 357-369. [CrossRef] [PubMed]

25. Han, X.; Shi, Y.; Si, L.; Fan, Z.; Wang, H.; Xu, R.; Jiao, P.; Meng, K.; Tian, Z.; Zhou, X.; et al. Design, synthesis and biological activity evaluation of novel conjugated sialic acid and pentacyclic triterpene derivatives as anti-influenza entry inhibitors. MedChemComm. 2016, 7, 1932-1945. [CrossRef]

26. Shi, Y.; Si, L.; Han, X.; Fan, Z.; Wang, S.; Li, M.; Sun, J.; Zhang, Y.; Zhou, D.; Xiao, S. Synthesis of novel pentacyclic triterpene-Neu5Ac2en derivatives and investigation of their in vitro anti-influenza entry activity. MedChemComm. 2017. [CrossRef]

27. Yu, M.; Si, L.; Wang, Y.; Wu, Y.; Yu, F.; Jiao, P.; Shi, Y.; Wang, H.; Xiao, S.; Fu, G.; et al. Discovery of pentacyclic triterpenoids as potential entry inhibitors of influenza viruses. J. Med. Chem. 2014, 57, 10058-10071. [CrossRef] [PubMed]

28. Wang, H.; Xu, R.; Shi, Y.; Si, L.; Jiao, P.; Fan, Z.; Han, X.; Wu, X.; Zhou, X.; Yu, F.; et al. Design, synthesis and biological evaluation of novel l-ascorbic acid-conjugated pentacyclic triterpene derivatives as potential influenza virus entry inhibitors. Eur. J. Med. Chem. 2016, 110, 376-388. [CrossRef] [PubMed]

29. Xiao, S.; Si, L.; Tian, Z.; Jiao, P.; Fan, Z.; Meng, K.; Zhou, X.; Wang, H.; Xu, R.; Han, X.; et al. Pentacyclic triterpenes grafted on cd cores to interfere with influenza virus entry: A dramatic multivalent effect. Biomaterials 2016, 78, 74-85. [CrossRef] [PubMed] 
30. Tian, Z.; Si, L.; Meng, K.; Zhou, X.; Zhang, Y.; Zhou, D.; Xiao, S. Inhibition of influenza virus infection by multivalent pentacyclic triterpene-functionalized per-O-methylated cyclodextrin conjugates. Eur. J. Med. Chem. 2017, 134, 133-139. [CrossRef] [PubMed]

31. Xiao, S.; Wang, Q.; Si, L.; Shi, Y.; Wang, H.; Yu, F.; Zhang, Y.; Li, Y.; Zheng, Y.; Zhang, C.; et al. Synthesis and anti-hcv entry activity studies of $\beta$-cyclodextrin-pentacyclic triterpene conjugates. ChemMedChem. 2014, 9, 1060-1070. [CrossRef] [PubMed]

32. Tropper, F.D.; Andersson, F.O.; Braun, S.; Roy, R. Phase-transfer catalysis as a general and stereoselective entry into glycosyl azides from glycosyl halides. Synthesis 1992, 618-620. [CrossRef]

33. Zemplén, G.; Pascu, E. The saponification acetyl sugar and relative substances. Ber. Deut. Chem. Ges. 1929, 62, 1613-1614. [CrossRef]

34. Longley, D.B.; Harkin, D.P.; Johnston, P.G. 5-fluorouracil: Mechanisms of action and clinical strategies. Nat. Rev. Cancer 2003, 3, 330-338. [CrossRef] [PubMed]

35. Mosmann, T. Rapid colorimetric assay for cellular growth and survival: Application to proliferation and cyto-toxicity assays. J. Immunol. Methods 1983, 65, 55-63. [CrossRef]

36. Chen, D.Y.; Shien, J.H.; Tiley, L.; Chiou, S.S.; Wang, S.Y.; Chang, T.J.; Lee, Y.J.; Chan, K.W.; Hsu, W.L. Curcumin inhibits influenza virus infection and haemagglutination activity. Food Chem. 2010, 119, 1346-1351. [CrossRef]

37. Chou, T.C.; Talalay, P. Quantitative-analysis of dose-effect relationships: The combined effects of multiple-drugs or enzyme-inhibitors. Adv. Enzyme Regul. 1984, 22, 27-55. [CrossRef]

38. Prescher, H.; Schweizer, A.; Kuhfeldt, E.; Nitschke, L.; Brossmer, R. Discovery of multifold modified sialosides as human CD22/Siglec-2 ligands with nanomolar activity on B-cells. ACS Chem. Biol. 2014, 9, 1444-1450. [CrossRef] [PubMed]

39. Hamilton, B.S.; Whittaker, G.R.; Daniel, S. Influenza virus-mediated membrane fusion: Determinants of hemagglutinin fusogenic activity and experimental approaches for assessing virus fusion. Viruses 2012, 4, 1144-1168. [CrossRef] [PubMed]

Sample Availability: Samples of the compounds studied in the present manuscript are available from the authors.

(c) 2017 by the authors. Licensee MDPI, Basel, Switzerland. This article is an open access article distributed under the terms and conditions of the Creative Commons Attribution (CC BY) license (http://creativecommons.org/licenses/by/4.0/). 